Review Article

\title{
The Current Consideration, Approach, and Management in Postcesarean Delivery Pain Control: A Narrative Review
}

\author{
L. Sangkum, T. Thamjamrassri, V. Arnuntasupakul, and T. Chalacheewa $(D)$ \\ Department of Anesthesiology, Faculty of Medicine, Ramathibodi Hospital, Mahidol University, Bangkok 10400, Thailand \\ Correspondence should be addressed to T. Chalacheewa; drtheerawat@gmail.com
}

Received 30 July 2021; Accepted 4 September 2021; Published 20 September 2021

Academic Editor: Ronald G. Pearl

Copyright (c) 2021 L. Sangkum et al. This is an open access article distributed under the Creative Commons Attribution License, which permits unrestricted use, distribution, and reproduction in any medium, provided the original work is properly cited.

\begin{abstract}
Optimal postoperative analgesia has a significant impact on patient recovery and outcomes after cesarean delivery. Multimodal analgesia is the core principle for cesarean delivery and pain management. For a standard analgesic regimen, the use of long-acting neuraxial opioids (e.g., morphine) and adjunct drugs, such as scheduled acetaminophen and nonsteroidal anti-inflammatory drugs, is recommended unless contraindicated. Oral or intravenous opioids should be reserved for breakthrough pain. In addition to the aforementioned use of multimodal analgesia, preoperative evaluation is critical to individualize the analgesic regimen according to the patient requirements. Risk factors for severe postoperative pain or analgesia-related adverse effects will require modifications to the standard analgesic regimen (e.g., the use of ketamine, gabapentinoids, or regional anesthetic techniques). Further investigation is required to determine analgesic drugs or dose alterations based on preoperative predictions for patients at risk of severe pain. Outcomes beyond pain and analgesic use, such as functional recovery, should be determined to evaluate analgesic treatment protocols.
\end{abstract}

\section{Introduction}

The rate of cesarean delivery has been increasing over the past decades, and it is one of the most commonly performed surgeries in the world, with nearly 18.5 million cesarean deliveries performed annually [1]. The causes to explain this higher trend including an increase in cesarean performed for maternal request, increased number of high-risk expectant mothers, changes in provider practice patterns, and the obstetrical medicolegal environment $[2,3]$.

Pain following cesarean delivery is a complex experience that is personalized to each patient. The degree of tissue injury triggers a response in the pain matrix, forming peripheral sensitization and central pain pathways to fear, anxiety, and frustration. Patients have reported concerns about pain during and after cesarean delivery as their highest priority [4]. The intensity and duration of pain experience increase the likelihood of greater opioid use, delayed recovery [5], and impeded maternal and fetal bonding [6]. Furthermore, severe acute pain is a strong risk factor for postpartum depression and chronic pain $[7,8]$, which results in long-term psychological, social, and economic adversities $[9,10]$. Therefore, optimal pain control is a key priority on both humanitarian grounds and for efficient health service delivery [11-13].

In addition to improving clinical outcomes and functional recovery. Enhanced recovery after surgery has been shown to lead to a reduction in complications and duration of hospital stay, as well as earlier resumption of normal activities [14]. Optimal pain control is a cornerstone of enhanced recovery after cesarean delivery (ERAC) $[15,16]$, and it is an essential component of the Obstetric Quality-ofRecovery (ObsQoR-10) score [17-19].

To optimize pain control with faster recovery and fewer side effects, stepwise multimodal analgesia is crucial for the management of postoperative pain. However, perioperative pain management should be individualized according to patient conditions (e.g., a history of chronic pain) or anesthetic techniques (general anesthesia or neuraxial anesthesia). This narrative review presents key considerations and approaches to the management of postoperative pain in cesarean delivery. 


\section{Identification of Women at Risk of Severe Postoperative Pain}

To optimize postoperative analgesia, pain management protocols have moved toward a standardized approach to personalized analgesic management. A large cohort study assessed pain resolution, opioid-free status, and functional recovery after vaginal and cesarean delivery. The time to pain resolution after delivery varied between 0 and 85 days [5]. This finding suggests that a standardized approach is not appropriate for the entire postpartum population and that pain management should target women at risk of severe or prolonged pain.

Several studies have evaluated patient risk factors during the preoperative period, including demographic and psychological factors and quantitative sensory tests (QSTs). In patients undergoing general surgery, female sex, younger age, preoperative anxiety, and a history of chronic pain were significant predictors of worse postoperative pain [20]. In patients undergoing cesarean delivery, several studies have investigated the role of preoperative QSTs or pain response to local anesthetic infiltration in predicting acute postoperative pain [21]. The correlations of preoperative QSTs (pressure, thermal, and electrical) with postoperative pain outcomes were weak to modest in most studies $[22,23]$. Therefore, the clinical role of preoperative QSTs is limited. The pain score upon local anesthetic infiltration was modestly associated with acute postoperative pain [21] as well as subacute postoperative pain [24]. Three simple questionnaires assessing anxiety, anticipated pain, and analgesic requirements were used to predict the upper $20^{\text {th }}$ percentile of the evoked pain score. The results revealed modest sensitivity (68\%) and specificity (67\%) [25]. However, the clinical use of the three simple questionnaires combined with the pain response to local anesthetic infiltration is easy to apply and may provide some value.

Another approach is giving patients more of a role in analgesic regimen selection. In a randomized controlled trial study, patients were selected to receive either high-dose $(200 \mathrm{mcg})$ or low-dose $(100 \mathrm{mcg})$ intrathecal morphine based on information regarding pain relief and side effects [26]. The results revealed that patients who requested the larger dose required more supplemental opioids and reported more pain than those who requested the smaller dose. Another study reported similar results, with patients choosing a higher dose $(300 \mathrm{mcg}$ intrathecal morphine + single dose oral gabapentin $600 \mathrm{mg}$ ) requiring more rescue opioids than those selecting a medium dose $(150 \mathrm{mcg})$ or low dose $(50 \mathrm{mcg})$ [27]. This finding confirmed that patients had insight into their pain needs. Patient-centered analgesic management may provide better patient expectations and outcomes based on individual preferences for pain relief and avoidance of side effects. Risk factors for severe postoperative pain after cesarean delivery are given in Table 1.

\section{Special Concerns about Pain Control in Cesarean Delivery}

Compared with other procedures, optimal pain control in cesarean delivery involves several key considerations:
(1) Preemptive analgesia is limited by concerns in utero fetal drug transfer

(2) The anesthetic technique is exclusively neuraxial anesthesia

(3) Potential analgesic drug transfer to breastfeeding neonates should be considered. Opioids are associated with breast milk transfer and may cause neonatal sedation. Therefore, opioid-sparing multimodal analgesia is preferable.

(4) The transition to oral medications as soon as possible is preferred. Early mobilization and enhancing the mother's ability to be independent and to care for her newborn baby is critical.

To achieve effective analgesia, postoperative opioid requirements and side effects should be decreased. Postcesarean delivery analgesia may be enhanced by many intraoperative interventions for multimodal analgesia, such as neuraxial opioids, nonopioid analgesics, regional blocks, or local analgesia infiltration.

3.1. Neuraxial Opioids. Neuraxial anesthesia is the preferred anesthetic technique for cesarean delivery [34]. Neuraxial anesthesia decreases maternal risk and improves fetal outcomes with the additional benefit of superior postoperative analgesia with the use of neuraxial opioids [35].

Neuraxial morphine binds to G-protein-like pre and postsynaptic opioid receptors in the dorsal horn, causing potassium channel opening and calcium channel closure, with an overall reduction in intracellular calcium. This reduces glutamate and substance $\mathrm{P}$ release from presynaptic $\mathrm{C}$ fibers and decreases nociceptive transmission [36]. In addition, neuraxial morphine spreads cephalad and binds to opioid receptors in the brain stem that indirectly activate the descending pain pathway, thus mitigating pain signaling [37].

3.2. Intrathecal Morphine. Intrathecal morphine is the gold standard single-shot drug for postcesarean pain. The duration of action of intrathecal morphine is between 14 and $36 \mathrm{~h}$ [38]. A meta-analysis revealed that high-dose intrathecal morphine $(100-250 \mathrm{mcg})$ prolonged analgesia after cesarean delivery compared with low-dose intrathecal morphine $(50-100 \mathrm{mcg})$ by $4.5 \mathrm{~h}$ ( $95 \%$ confidence interval (CI), 1.9-7.1). Both groups had comparable pain scores and $24 \mathrm{~h}$ morphine consumption. However, a lower dose of intrathecal morphine was associated with a lower incidence of nausea or vomiting (OR, 0.44; 95\% CI, 0.27-0.73) and pruritus (OR, 0.34; 95\% CI, 0.2-0.59) [39]. None of the studies in this meta-analysis reported respiratory depression in any of the patients.

As part of multimodal analgesia, a randomized doubleblinded control study determined the dose response of intrathecal morphine when administered with intravenous ketorolac. The results suggested that $50 \mathrm{mcg}$ intrathecal morphine produces analgesia similar to that produced by either $100 \mathrm{mcg}$ or $150 \mathrm{mcg}$ [40]. In summary, increasing 
TABLE 1: Risk factors for severe postoperative pain after cesarean delivery.

\begin{tabular}{|c|c|c|}
\hline Patient related factors & Questionnaire and quantitative sensory testing & iisk factors \\
\hline $\begin{array}{l}\text { Preoperative anxiety }[28,29] \\
\text { Previous cesarean delivery [30] } \\
\text { History of chronic pain or history of } \\
\text { chronic opioid use [20] }\end{array}$ & $\begin{array}{c}\text { Quantitative sensory testing: electrical pain threshold [31], } \\
\text { heat pain threshold [32], and local infiltration [21] } \\
\text { Three simple questions (level of anxiety, anticipated pain, } \\
\text { and analgesics need) [25] }\end{array}$ & $\begin{array}{l}\text { cal rating score for } \\
24 \text { hours [33] }\end{array}$ \\
\hline
\end{tabular}

doses of intrathecal morphine extended the analgesic duration following cesarean delivery but increased the risk of side effects (e.g., nausea and itching). Using intrathecal morphine as part of a multimodal analgesic regimen, the optimal dose of intrathecal morphine is between 50 and $100 \mathrm{mcg}$.

3.3. Epidural Morphine. Eventhough most cesarean deliveries are performed mainly with spinal anesthesia [41], unplanned cesarean deliveries are often performed on patients in labor with epidurals in situ. For these patients, epidural catheters can be used for the administration of epidural morphine. However, the optimal dose of epidural morphine is unclear, and dosing has been based on intrathecal morphine equivalency studies and dose-finding studies. Equipotent dosing (equianalgesic dose) requires a conversion ratio of $20: 1-30: 1$ between epidural and intrathecal administration $[42,43]$. The optimal dose was $3 \mathrm{mg}$ in a large retrospective study [44] and $3.75 \mathrm{mg}$ in a doseresponse study [45]. In a randomized controlled trial study of 87 elective cesarean deliveries under combined spinal epidural anesthesia, $24 \mathrm{~h}$ opioid consumption of epidural morphine $1.5 \mathrm{mg}$ and $3 \mathrm{mg}$ was compared. No significant difference was observed in postcesarean delivery analgesia between the groups, but epidural morphine $1.5 \mathrm{mg}$ led to fewer side effects. However, this study included acetaminophen and ketorolac as part of the multimodal regimen, which may have mitigated the analgesic differences between the lower and higher epidural morphine dose groups [46].

Neuraxial morphine is well known for its high-quality postcesarean delivery, pain control, simplicity of administration, and cost-effectiveness [38]. Therefore, neuraxial morphine is currently regarded as the gold standard for analgesia following cesarean delivery. However, neuraxial morphine has known side effects. To minimize dose-related adverse effects, the optimal dose is a balance between optimal analgesia and minimal side effects. The ideal dose for a "single-shot" intrathecal dose appears to be $50-100 \mathrm{mcg}$, and the "single-shot" epidural morphine dose is $1.5-3 \mathrm{mg}$ when used in multimodal analgesia.

3.4. Regional Blocks for Cesarean Section. Regional anesthesia is strongly advocated within a nonobstetric surgical setting as part of multimodal analgesic strategies [47]. As part of the ERAC program, if neuraxial morphine cannot be administered, regional anesthesia plays a significant role in postoperative analgesia. Regional anesthesia improves analgesia and decreases postoperative opioid requirements. Moreover, the use of regional anesthesia may be beneficial to provide relief from severe incisional pain or for patients at risk for severe acute pain [48]. There are several regional anesthesia techniques as follows.

\subsection{Local Anesthetic Wound Infiltration and Infusion.}

Local anesthetic wound infiltration and infusion are alternative strategies to reduce IV and oral opioid consumption and decrease opioid-related side effects. A meta-analysis included single-shot and continuous wound infusion in patients undergoing cesarean delivery with and without intrathecal morphine. The results showed that these techniques provided an opioid-sparing effect (mean difference $-9.69 \mathrm{mg}$ of morphine equivalents $(95 \% \mathrm{CI}-14.85$ to -4.52$)$ ) but had a minimal effect on pain scores (mean difference $-0.36,95 \%$ CI -0.58 to -0.14 ) [49]. In the subgroup analysis, $24 \mathrm{~h}$ morphine consumption and $24 \mathrm{~h}$ pain score at rest and with movement were significantly decreased in patients who did not receive intrathecal morphine. However, $24 \mathrm{~h}$ pain scores with movement and $24 \mathrm{~h}$ morphine consumption had no statistically difference in patients who received intrathecal morphine. Therefore, the addition of anesthetic wound infiltration and infusion in patients who received intrathecal morphine seems to have limited benefit [50].

Single-shot wound infiltration in cesarean delivery has a limited analgesic duration of $4-12 \mathrm{~h}[51,52]$. Therefore, continuous wound infiltration is preferred over a single injection. With respect to the catheter placement site, subfascial catheters are preferred over above-fascial catheters, as they showed lower pain at rest and less total morphine consumption than above-fascial catheters [53]. The hypothesized better outcomes in the use of subfascial catheters are probably due to an anti-inflammatory effect of the local anesthetic, which is absorbed intraperitoneally, and less leakage with subfascial infusion. Various agents and infusion parameters have been studied in cesarean delivery, such as continuous infusion vs. intermittent infusion or the addition of NSAIDs to the local anesthetic [50,54-56]. To date, the optimal agents, dose of local anesthesia, and infusion regimen remain inconclusive.

Liposomal bupivacaine infiltration administered above and below the fascial layer and within the subcutaneous tissue in patients who received intrathecal morphine showed that wound infiltration with liposomal bupivacaine can reduce postoperative pain scores without increasing side effects [57]. However, the opposite result was also reported [58].

In conclusion, local anesthetic wound infiltration and wound infusion have opioid-sparing effects in woman undergoing cesarean delivery under general anesthesia or where intrathecal morphine has been omitted. Subfascial continuous wound infusion is preferable to a single 
infiltration. Data in women receiving multimodal analgesia, including intrathecal morphine, are sparse and suggest limited benefit $[49,59]$. The use of liposomal bupivacaine infiltration requires further evaluation in cesarean delivery.

3.6. Bilateral Transversus Abdominis Plane (TAP) Blocks. The TAP block is an abdominal field block between the internal oblique and transversus abdominis muscles that contain $7^{\text {th }}-11^{\text {th }}$ intercostal nerves and the ilioinguinal and iliohypogastric nerves [60]. In 2008, the first trial investigating bilateral TAP blocks for cesarean delivery was performed with the loss of the resistance technique at the triangle of Petit [61]. All patients received a standard spinal anesthesia with intrathecal fentanyl $25 \mu \mathrm{g}$, rectal diclofenac $1 \mathrm{mg} / \mathrm{kg}$, and rectal acetaminophen $1 \mathrm{~g}$ at the end of surgery. The results revealed that bilateral TAP blocks provided superior analgesia up to $48 \mathrm{~h}$ compared with placebo. The point of injection plays a central role in local anesthetic spreading. A posterior approach to the TAP block provides more spread to the paravertebral space and therefore improved analgesic efficacy compared with the lateral approach [62].

Multiple randomized controlled studies, including the posterior or lateral TAP block for multimodal analgesia, indicated that bilateral TAP blocks had analgesic benefits and opioid-sparing effects compared with placebo. However, the TAP block provides mainly somatic pain but not visceral pain relief, and it has a limited analgesic duration of 6-12 h, whereas intrathecal morphine has analgesic effects up to $36 \mathrm{~h}$. Therefore, compared with intrathecal morphine (100-200 mcg), bilateral TAP blocks provide inferior analgesic efficacy, but they have a lower incidence of opioidrelated side effects. In addition, the combination of bilateral TAP blocks to intrathecal morphine did not improve analgesic efficacy or decrease opioid consumption in patients [63]. To overcome the short analgesic effect, liposomal bupivacaine was used for bilateral TAP blocks as part of a multimodal analgesic regimen incorporating $150 \mu \mathrm{g}$ intrathecal morphine, ibuprofen, and acetaminophen. The bilateral TAP blocks with the liposomal bupivacaine group had a significant opioid-sparing effect of $52 \%$ in the first $72 \mathrm{~h}$ and $49 \%$ at 1 week [64].

However, the TAP block may cause local anesthetic systemic toxicity in cesarean delivery $[65,66]$. Obstetric patients are susceptible to local anesthetic toxicity as they have increased sensitivity of nerve axons, higher cardiac output, and less protein binding [67]. Therefore, the minimal effective dose of local anesthetic is highly recommended for this population. A meta-analysis showed no difference in analgesic efficacy between high dose (bupivacaine equivalent $>50 \mathrm{mg} /$ side) and low dose (bupivacaine equivalent $\leq 50 \mathrm{mg} /$ side) [68]. However, because the TAP block is a plane block, the volume of anesthesia should be considered, as it may affect the spreading of local anesthetics and analgesic efficacy. Therefore, the minimum local anesthetic volume is recommended to be $\geq 15 \mathrm{~mL}$ per side $[69,70]$.

In summary, bilateral posterior and lateral approach TAP blocks provide a valuable analgesic option in patients who cannot receive intrathecal morphine. A posterior approach bilateral TAP blocks is preferred over a lateral approach because it provides more effective analgesia. A bilateral TAP blocks may also be used as a rescue technique in patients with severe incisional pain after cesarean delivery.

3.7. Bilateral Quadratus Lumborum (QL) Blocks. A QL block is a fascial plane block where a local anesthetic is injected adjacent to the quadratus lumborum muscle into the thoracolumbar fascia layer. The dermatomes that are affected by QL block depend on the approach and vary from T6 to L4 [71-73]. The plausible mechanism of action is to block the thoracic nerves and the sympathetic thoracic trunk of the lower thoracic level [71]. In addition, the thoracolumbar fascia has extensive sensory innervation by both $\mathrm{A}$ and $\mathrm{C}$ fiber nociceptors and causes sympathetic afferent sympathetic blockade [74]. Because the QL block involves a more posterior approach than the TAP block, the local anesthetic is likely to spread into the paravertebral space. Therefore, the QL block potentially provides analgesia for both somatic and visceral pain and theoretically provides improved analgesia compared to the TAP block [75].

In 2015, the first bilateral QL blocks randomized doubleblinded study was conducted to compare bilateral lateral approach QL blocks and control groups in patients undergoing cesarean delivery. All patients in both groups did not receive intrathecal morphine. The patients who received bilateral QL blocks had significantly lower pain scores up to $48 \mathrm{~h}$ (VAS at rest: $0(0-1)$ vs. $0(0-3), P=0.004)$ and lower morphine consumption ( $48 \mathrm{~h}$ morphine use: 11 (4.5-18) vs. 20 (13.0-48), $P=0.012$ ) than the control group [76]. A metaanalysis by $\mathrm{Xu}$ et al. [77] and Tan et al. [78] showed that bilateral QL blocks provided greater analgesia and reduced postoperative opioid consumption in patients who did not receive intrathecal morphine.

When comparing neuraxial morphine with bilateral QL blocks, Pangthipampai et al. showed that patients who received intrathecal morphine $(200 \mathrm{mcg})$ had lower VAS scores at rest $(1(0-2)$ vs. $3[1-5], P=0.011)$ and lower $24 \mathrm{~h}$ morphine consumption (5.5 (0-25) vs. $20(1-46), P=0.006)$ than patients who received bilateral posterior approach $\mathrm{QL}$ blocks (0.25\% bupivacaine $25 \mathrm{~mL}$ each side) [79]. Several randomized controlled trials have also reported a greater analgesic efficacy of intrathecal or epidural morphine over bilateral QL blocks [80, 81]. However, one study showed inconsistent results [82]. A meta-analysis found insufficient evidence regarding postoperative opioid use or pain scores with the use of bilateral QL blocks compared with intrathecal morphine [77].

In terms of the addition of a bilateral QL blocks as part of multimodal analgesia, Tamura et al. compared the postoperative analgesic effect in patients who received posterior approach bilateral QL blocks with and without intrathecal morphine $(100 \mathrm{mcg})$ [80]. The results revealed that both groups had comparable analgesic outcomes [80]. Similar results were reported by Irwin et al. [83]. A meta-analysis concluded that the inclusion of bilateral QL blocks as part of multimodal analgesia in patients who received intrathecal or 
epidural morphine does not provide better analgesia either at rest or during movement at $24 \mathrm{~h}$ or lower $24 \mathrm{~h}$ morphine consumption [77, 78].

Regarding potential side effects, the peak concentration of local anesthetic is lower after bilateral QL blocks than after bilateral TAP blocks [84]. However, local anesthetics can cause systemic toxicity or hematoma from bleeding because of the presence of lumbar arteries, which are located at the posterior and lateral aspect of the QL muscle. Moreover, lower limb weakness and hypotension have been reported after the QL block due to the local anesthetic spreading to the lumbar plexus [85] and paravertebral space [86]. Therefore, these adverse effects should be considered in patients who received the QL block.

In summary, based on the current knowledge, bilateral QL blocks provided analgesic benefits in patients who did not receive neuraxial morphine. Bilateral QL blocks were shown to reduce opioid consumption and pain scores when compared with bilateral TAP blocks. The addition of bilateral QL blocks to patients who received neuraxial morphine did not improve the analgesic benefits.

The possible advantages and disadvantages of each regional anesthetic technique are given in Table 2.

\subsection{Nonsteroidal Anti-Inflammatory Drugs (NSAIDs).} NSAIDs are analgesic, antipyretic, and anti-inflammatory drugs that inhibit the cyclooxygenase enzyme (COX) pathway of prostaglandin production. NSAIDs reduce postoperative morphine consumption by $30 \%-50 \%$ after major surgery [89] and cesarean delivery [90, 91], thereby reducing the incidence of opioid-related side effects after surgery. NSAIDs also have very low breast milk transfer, and most NSAIDs are listed by the American Academy of Pediatrics as safe to use during breastfeeding. Therefore, NSAIDs are endorsed by enhanced recovery after surgery (ERAS), the Society for Obstetric Anesthesia and Perinatology (SOAP), and the American College of Obstetrician and Gynecologists (ACOG) for use as part of a multimodal analgesic regimen $[15,16,92]$.

Ketorolac is one of the popular intravenous NSAIDs that can be administered via the intravenous or intramuscular (IM) route. In a randomized double-blinded control study of 44 elective cesarean deliveries, intravenous ketorolac $30 \mathrm{mg}$ reduced the $24 \mathrm{~h}$ use of morphine by $31.7 \%$ [93]. Parecoxib is another intravenous NSAID that has been approved in European and Asian countries and in Mexico. A single dose of intravenous parecoxib did not reduce postoperative morphine consumption, but it reduced postoperative pain scores with higher patient satisfaction [94]. With respect to NSAIDs in oral or suppository form, naproxen [95], ibuprofen [96], celecoxib [97], and diclofenac suppositories $[98,99]$ are mostly effective compared with placebo (Table 3). However, there are no studies that compare the analgesic efficacy of different NSAIDs.

In summary, for women undergoing cesarean delivery, scheduled NSAIDs should be administered in the postpartum period in the absence of contraindications. The type of NSAIDs should be based on the patient's condition (e.g., a history of dyspepsia), drug availability, and drug safety profile while breastfeeding $[15,16,92,100]$.

3.9. Acetaminophen. Acetaminophen is the most common analgesic used worldwide and has a long record of safe use and few side effects. Acetaminophen inhibits peroxidase, leading to a reduction in prostaglandin formation [108]. Therefore, acetaminophen has analgesic and antipyretic effects. The mechanism of action of acetaminophen is also proposed as interference with the descending serotonergic pain pathways and weak binding to cannabinoid receptors, which inhibits nitric oxide production in the spinal cord and modulates nociceptive transmission [109].

The inclusion of acetaminophen in multimodal analgesia produces opioid-sparing effects. A significant reduction in $24 \mathrm{~h}$ morphine consumption is observed with acetaminophen compared with placebo after major surgery [89] and cesarean delivery [110]. A summary of the relevant studies is given in Table 4. Therefore, acetaminophen has been recommended as a component of postcesarean delivery analgesia in various guidelines $[15,16,92,100]$ due to its safety profile at regular doses [111]; improved efficacy of analgesia, especially when it is combined with NSAIDs [112, 113]; and reduced breast milk penetration [114].

In a retrospective study of patients who received intrathecal morphine and scheduled acetaminophen for $48 \mathrm{~h}$, patients who received scheduled oral acetaminophen needed less intravenous morphine than the as-needed group $(13.8 \pm 14.3$ vs. $23.0 \pm 17.7 \mathrm{mg}, P \leq 0.001)$ [115]. Comparing oral and intravenous acetaminophen, a randomized controlled trial of 141 patients undergoing cesarean delivery showed no difference in opioid consumption between groups but reduced opioid consumption when compared with those who received no acetaminophen [116].

Because combining acetaminophen and NSAIDs has an additive analgesic effect, both drugs should be administered routinely after cesarean delivery $[15,16,92,100,113]$. Intravenous forms of both acetaminophen and NSAIDs are not recommended, as they lack clear evidence and cause higher costs. Intravenous administration should be reserved for patients who cannot tolerate oral intake or those who develop nausea or vomiting.

3.10. Steroids. Steroids are well known as the drug of choice for the prevention of postoperative nausea and vomiting [121]. Moreover, steroids also have an analgesic property by inhibiting the conversion of phospholipase A2 to arachidonic acid, which is the precursor of prostaglandin formation.

Four randomized controlled trials evaluated the use of intravenous dexamethasone $8-10 \mathrm{mg}$ [122-125]. The results revealed that intravenous dexamethasone reduced modest pain scores, improved patient recovery outcomes [126], and prolonged postoperative analgesia [122] in patients undergoing cesarean section under spinal anesthesia. A metaanalysis of patients who received neuraxial morphine, including four trials of cesarean delivery and four abdominal hysterectomies, showed that a single dose of dexamethasone 
TABLE 2: Comparison efficacy of regional anesthetic techniques on analgesic efficacy.

\begin{tabular}{lcc}
\hline & Possible advantages & Possible disadvantages \\
\hline $\begin{array}{l}\text { Single-shot local anesthetic } \\
\text { wound infiltration }\end{array}$ & $\begin{array}{c}\text { Easy to perform } \\
\text { May benefit patients who did not receive } \\
\text { intrathecal morphine [49] }\end{array}$ & $\begin{array}{c}\text { Provides only somatic pain relief } \\
\text { Limited duration of action: 4-12 h [51, 52] }\end{array}$ \\
\hline $\begin{array}{l}\text { Continuous wound infusion } \\
\text { Bilateral transversus abdominis } \\
\text { plane blocks }\end{array}$ & $\begin{array}{c}\text { Decreased opioid consumption [53] } \\
\text { Duration of action: 6-12 h [63] }\end{array}$ & $\begin{array}{c}\text { Provides only somatic pain relief } \\
\text { Risk of leakage [53] } \\
\text { Risk of dislodge [53] }\end{array}$ \\
\hline $\begin{array}{l}\text { Bilateral quadratus lumborum } \\
\text { blocks }\end{array}$ & $\begin{array}{c}\text { Decreased opioid consumption [77, 78] } \\
\text { Duration of action up to 24-48 h [76, 87] }\end{array}$ & $\begin{array}{c}\text { Provides only somatic pain relief [60] } \\
\text { other techniques [65, 84] }\end{array}$ \\
\hline
\end{tabular}

decreased pain scores compared with the placebo (mean difference $(95 \% \mathrm{CI}=-0.30(-0.46,-0.13))$ and reduced the use of rescue analgesics $(\mathrm{RR}(95 \% \mathrm{CI})=0.72(0.52,0.98))$ [127]. However, the side effects of dexamethasone include elevated postoperative blood glucose levels, increased risk of wound infection, and delayed wound healing. A metaanalysis reported that single dose dexamethasone did not increase the incidence of delayed wound healing or increase the risk of infection [127]; nevertheless, dexamethasone should be avoided in patients with insulin resistance. The effect of elevated blood glucose levels appeared to be increased in a dose-dependent manner.

Thus, eventhough single dose dexamethasone did not clinically improve pain scores, it reduced the need for rescue analgesia by $30 \%$ and had antiemetic properties [127]. Therefore, the procedure-specific postoperative pain management (PROSPECT) guidelines recommended using a single intravenous dose of dexamethasone for cesarean delivery in the absence of contraindications [100]. However, other guidelines still do not endorse intravenous dexamethasone in routine use $[15,16,92]$. The risks and benefits should be evaluated in terms of the use of steroids.

3.11. Ketamine. In recent years, multiple research trials have suggested the usefulness of ketamine as a strong analgesic when used in subanesthetic intravenous doses. The proposed mechanism of ketamine is the blockade of postsynaptic N-methyl-D-aspartate (NMDA) receptors, neuronal hyperpolarization-activated cationic currents, nicotinic acetylcholine ion channels, and delta and mu-opioid receptors [128]. Ketamine may also reduce cholinergic neuromodulation $[129,130]$ and enhance the inhibitory serotoninergic pathway [131].

In 2005, the first subanesthetic intravenous doses of ketamine $(0.15 \mathrm{mg} / \mathrm{kg})$ were administered to patients undergoing cesarean delivery under spinal anesthesia. The results revealed that ketamine prolonged the time to the first analgesic requirement $(53 \mathrm{~min})$ and decreased the total analgesic consumption and pain score [132]. Han et al. used a larger dose of ketamine $(0.5 \mathrm{mg} / \mathrm{kg}$ intravenous bolus, followed by $0.25 \mathrm{mg} / \mathrm{kg} / \mathrm{h}$ continuous infusion) during surgery [133]. In the ketamine group, there was significantly less fentanyl use at $2 \mathrm{~h}$ after surgery $(58.0 \pm 27.5$ vs. $81.2 \pm 30.4 \mathrm{mg}, P=0.033$ ) but no statistically significant difference at 6, 24, or $48 \mathrm{~h}$ after surgery. Pain scores at 2, 6, 24 , and $48 \mathrm{~h}$ were comparable between groups [133]. Bauchat et al. conducted a randomized controlled trial of ketamine $10 \mathrm{mg}$ IV as part of a multimodal analgesia regimen (intrathecal morphine $150 \mu \mathrm{g}$ and ketorolac $30 \mathrm{mg}$ IV every $6 \mathrm{~h}$ ) [134]. The pain score and $24 \mathrm{~h}$ opioid consumption were not different at 24,48 , or $72 \mathrm{~h}$. However, at 2 weeks postpartum, the ketamine group had lower pain scores than the control group (difference $-0.6,95 \% \mathrm{CI}-1.1$ to -0.9 ). Regarding side effects, more patients in the ketamine group reported being drowsy, restless, lightheaded, dizzy, or having double vision [134].

A recent meta-analysis evaluated the analgesic effect of low doses of ketamine in 20 cesarean delivery studies (general anesthesia was administered in seven studies and spinal anesthesia in five studies) [135]. The results revealed that ketamine enhanced postoperative analgesia for 49.36 min (95\% CI 43.31-55.41) after cesarean delivery under spinal anesthesia. Visual analogue scale pain scores at rest $2 \mathrm{~h}$ after surgery were significantly lower in the ketamine group, and no differences were noted in maternal nausea, vomiting, pruritus, or psychommetric effects between groups [135].

Currently, ketamine is not recommended as a routine drug for postoperative pain strategies. However, the addition of ketamine as part of a multimodal regimen may be effective in patients with escalating opioid requirements or in women with a history of chronic pain [136].

3.12. Gabapentinoids. Gabapentinoids inhibit the $\alpha_{2} \delta$ subunit of calcium channels and enhance the inhibitory serotoninergic pathway. Gabapentinoids are the most commonly used to manage chronic neuropathic pain. Their use in the perioperative period was proposed, as trials suggested that gabapentinoids may have a protective effect and prevent persistent postsurgical pain [137] and reduce opioid consumption in the early postoperative period [138].

Gabapentinoids as an adjunct analgesic for cesarean delivery have been evaluated. In a randomized control study, preoperative oral gabapentin $600 \mathrm{mg}$ was administered $1 \mathrm{~h}$ 


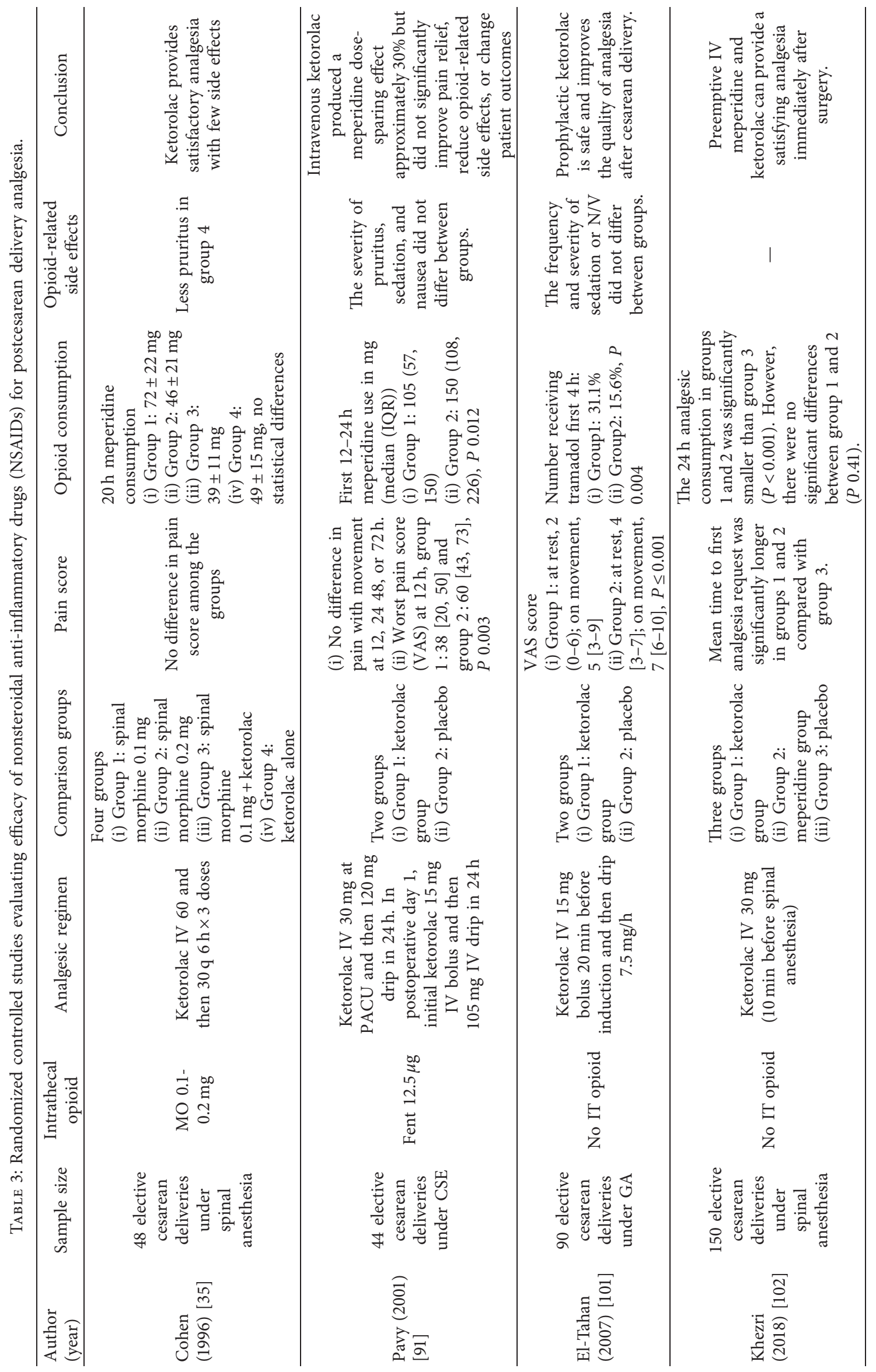




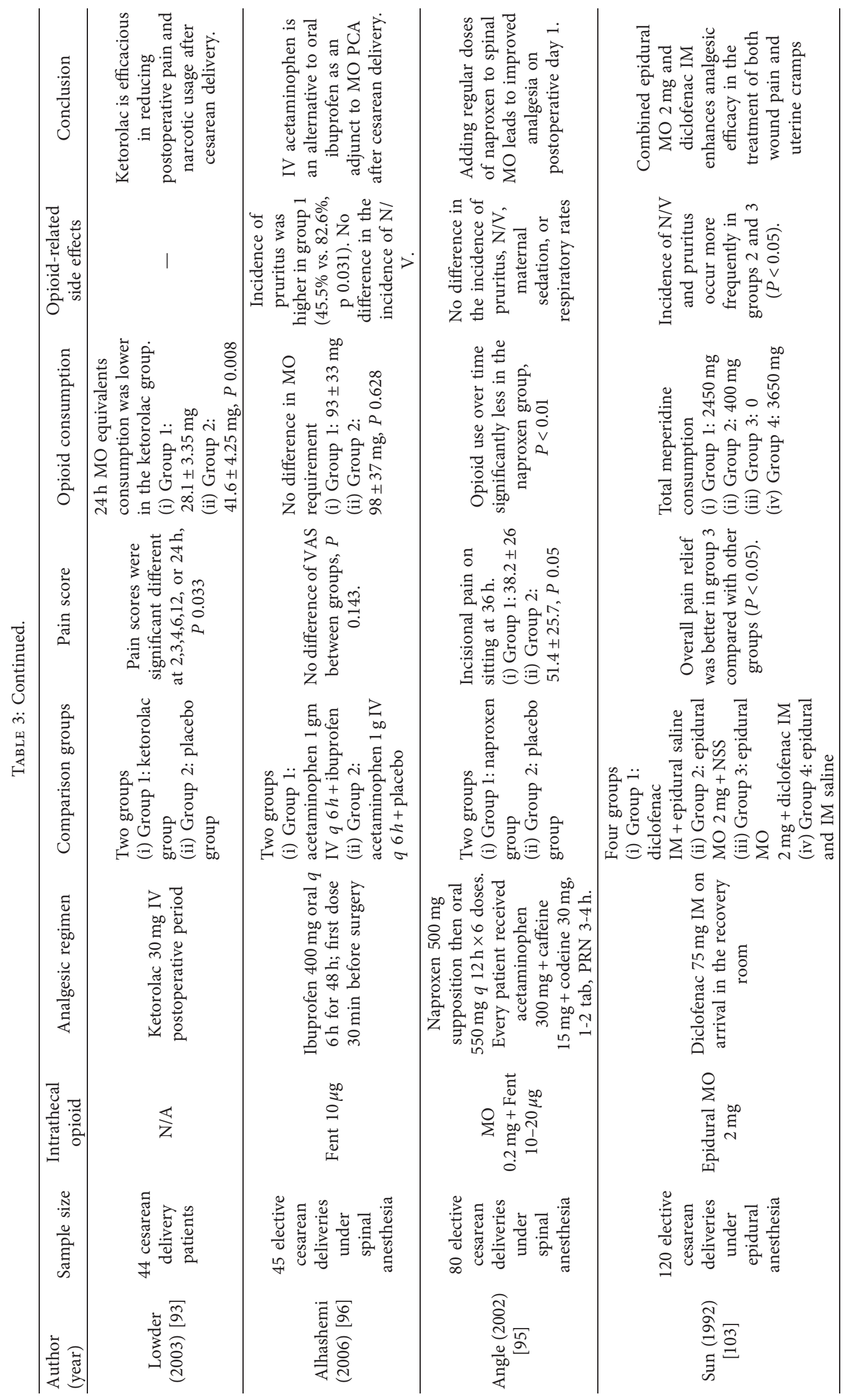




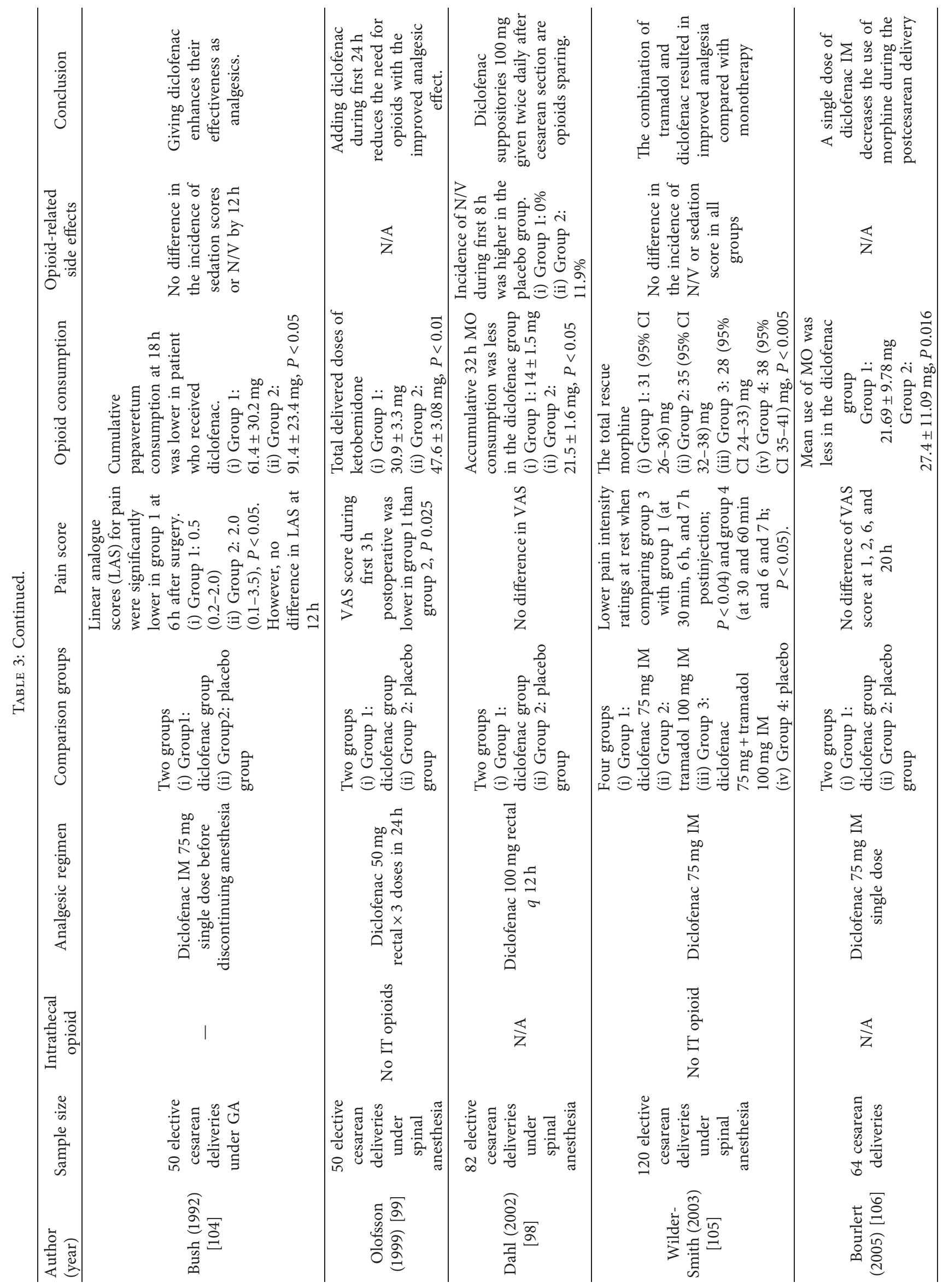




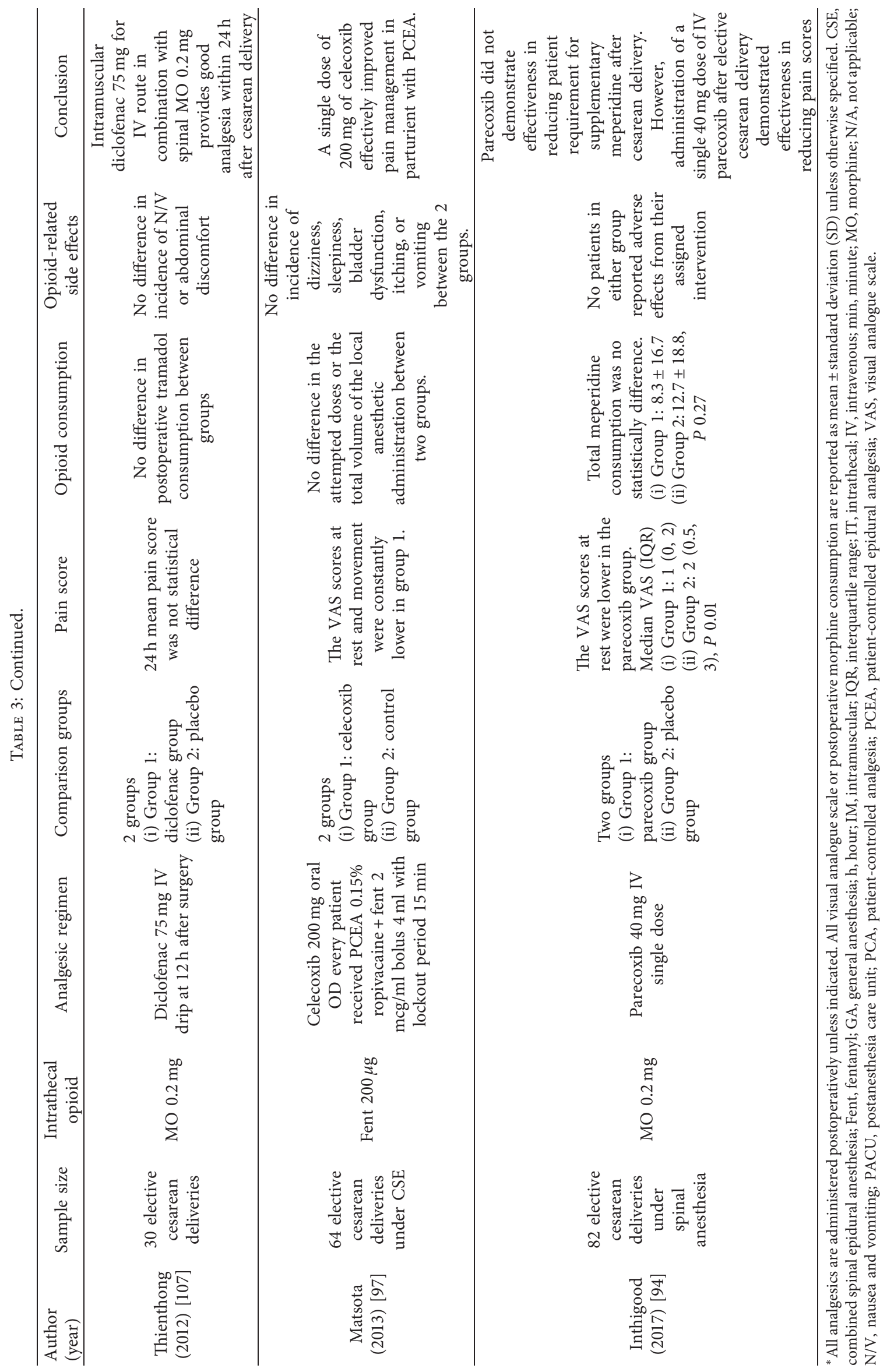




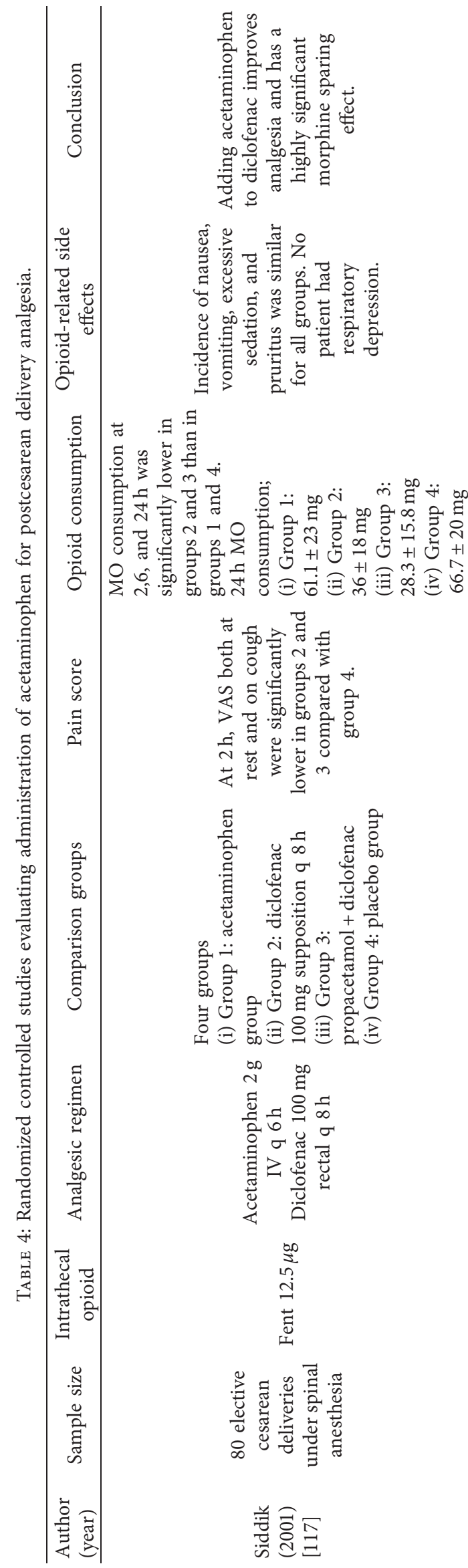

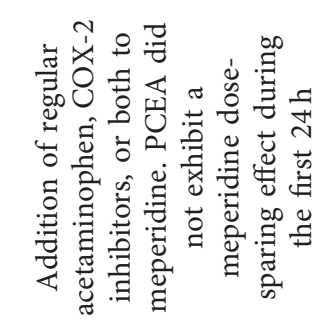

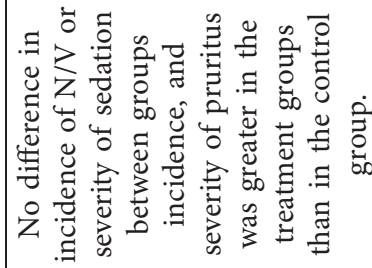

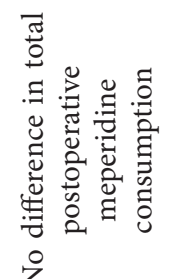

之े

范节

$\exists$ 盯

节芯莒

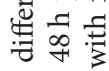

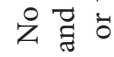

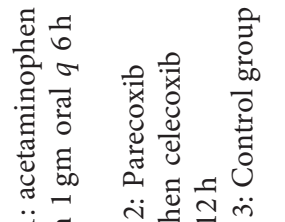

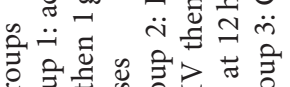

क力

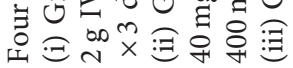

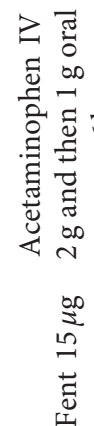

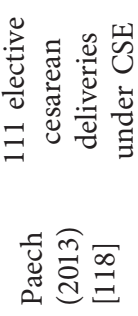

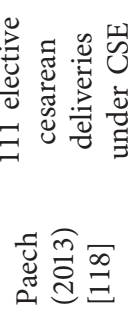

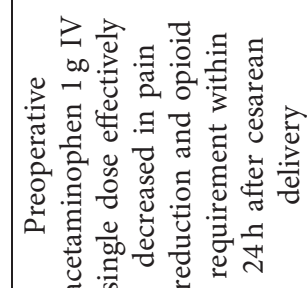

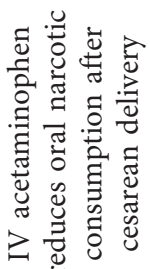

$\stackrel{\Xi}{\ddagger}$

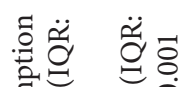

焗

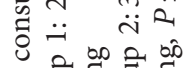

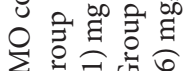

다아

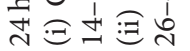

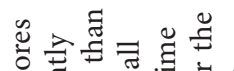

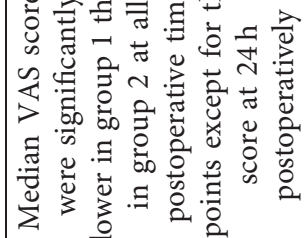

过

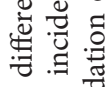

之

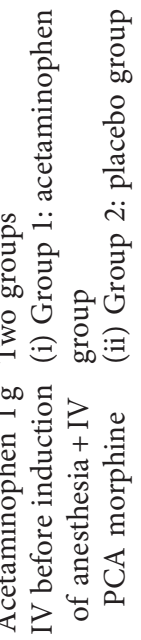

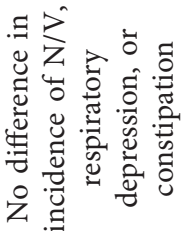

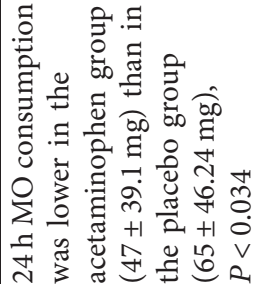

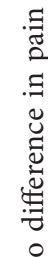

苛

承

ż

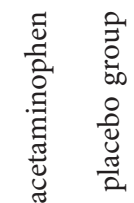

言苛

कू

坣 $\cong$ 品

요

चี

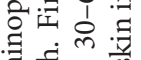

घี

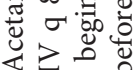

$\overleftrightarrow{\mathrm{Z}}$

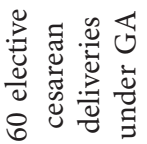

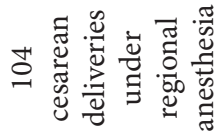

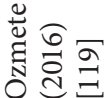

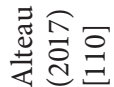




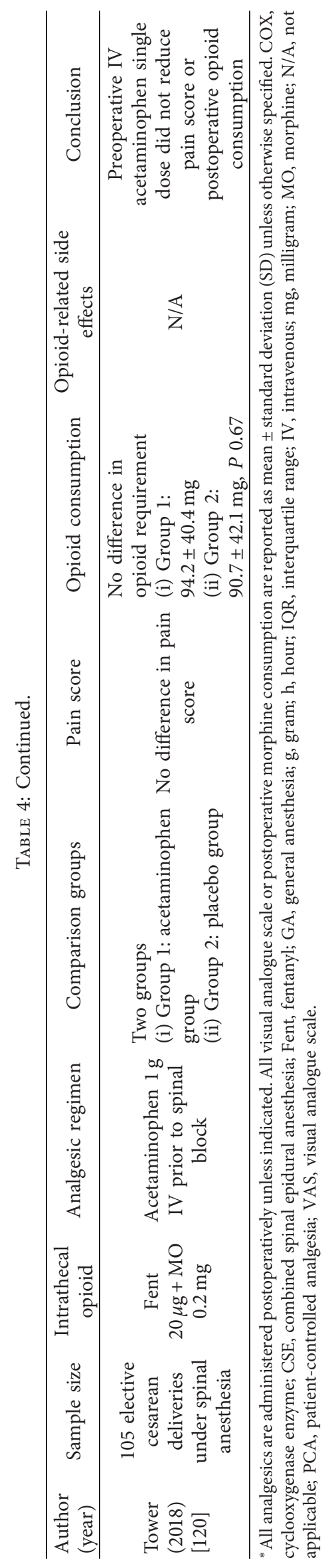


TABle 5: Postoperative analgesic recommendation for cesarean delivery.

\begin{tabular}{|c|c|c|c|}
\hline & SOAP consensus statement [6] & ERAS society [7] & PROSPECT guideline [37] \\
\hline Morphine & $\begin{array}{l}\text { Neuraxial long-acting opioid example: } \\
\text { Intrathecal morphine } 50-150 \mathrm{mcg} \text { or } \\
\text { epidural morphine } 1-3 \mathrm{mg}\end{array}$ & $\begin{array}{l}\text { Long-acting intrathecal opioids such } \\
\text { as morphine provides analgesia for } \\
\text { several hours after cesarean delivery, } \\
\text { although the expense of a number of } \\
\text { side effects include nausea, vomiting, } \\
\text { and pruritus. }\end{array}$ & $\begin{array}{l}\text { Intrathecal morphine } 50-100 \mathrm{mcg} \text { or } \\
\text { diamorphine } 300 \mathrm{mcg} \text {. Epidural } \\
\text { morphine } 2-3 \mathrm{mg} \text { or diamorphine } \\
2-3 \mathrm{mg} \text { may be administered as an } \\
\text { alternative. }\end{array}$ \\
\hline
\end{tabular}

NSAIDs analgesia started in OR

unless contraindicated:

Acetaminophen (i) Ketorolac 15-30 mg IV after Regular NSAID and acetaminophen Acetaminophen peritoneum closed

(ii) Acetaminophen IV after delivery or orally, per oral before or after delivery are recommended for enhanced recovery for cesarean delivery.
Prescribe acetaminophen and a

NSAID administered after delivery and continued regularly postoperatively.

A single dose of IV dexamethasone after delivery in the absence of contraindication

Dexamethasone $-$

In the absence of long-acting intrathecal opioids, the TAP field block provides excellent

Consider local anesthetic wound

Local anesthetic techniques infiltration or regional blocks such as bilateral TAP or QL blocks if neuraxial morphine is not administered. postoperative pain control. A

Cochrane review of local analgesia infiltration and abdominal nerve blocks found that they improved postoperative analgesia for cesarean delivery.

ERAS, enhanced recovery after surgery; IV, intravenous; NSAID, nonsteroidal anti-inflammatory drug; PROSPECT, procedure-specific postoperative pain management; OR, operating room; QLB, quadratus lumborum block; SOAP, Society for Obstetric Anesthesia and Perinatology; TAP, transversus abdominis plane block.

before surgery as part of a multimodal analgesia regimen (intrathecal morphine $100 \mathrm{mcg}$, oral diclofenac $50 \mathrm{mg}$ every $8 \mathrm{~h}$, and acetaminophen $1 \mathrm{~g}$ every $6 \mathrm{~h}$ ). The pain score (visual analogue scale $0-100 \mathrm{~mm}$ ) on movement at $24 \mathrm{~h}$ was $21 \mathrm{~mm}$ (95\% CI 13-28) in the gabapentin group and $41 \mathrm{~mm}$ (95\% CI $31-50)$ in the placebo group $(P=0.001)$, without a significant difference in opioid consumption. Severe maternal sedation was observed more often in the gabapentin group (19\% vs. $0 \%, P=0.04$ ) [139]. Monks et al. used a larger dose of oral gabapentin $600 \mathrm{mg}$ preoperatively followed by $200 \mathrm{mg}$ every $8 \mathrm{~h}$ for 2 days [140]. The results revealed that there was a small reduction in pain score $(-7 \mathrm{~mm}(-13$ to 0$) ; P=0.047)$ with greater patient satisfaction in the gabapentin group $(87$ vs. $77 \mathrm{~mm}, P=0.003$ ) [140]. However, gabapentin produced a significantly higher incidence of sedation (55\% vs. $39 \%$, $P=0.026)$ [140]. In contrast, Short et al. reported no significant analgesic benefits with gabapentin compared with placebo [141]. A meta-analysis of cesarean delivery under spinal anesthesia reported that gabapentin significantly reduced the pain score on movement at $24 \mathrm{~h}$ (mean difference $-11.58,95 \%$ CI -23.04 to -0.12 ). However, pain scores at other time points at rest or on movement were not significantly different [142].

There are several limitations of gabapentinoid use. First, gabapentinoids have a high umbilical vein-to-maternal vein ratio. Therefore, gabapentinoids should be avoided as preemptive administrations in patients undergoing cesarean delivery [139]. Second, gabapentinoids cause maternal side effects (e.g., sedation and visual disturbance). Moreover, current evidence still fails to demonstrate a strong benefit of gabapentinoids on postoperative pain in cesarean delivery, as well as the potential adverse effects and neonatal safety profile [143]. Therefore, gabapentinoids are still not recommended for routine use in postcesarean analgesia. However, they can be considered as a part of multimodal analgesia to decrease opioid consumption or improve pain relief in patients with chronic pain [136].

\subsection{Evaluation of Recovery Function beyond the Pain Score.} Effective postoperative pain management is paramount for faster recovery. A good pain score does not imply that the patient has good functional recovery. As an example, a prospective observational study using activity trackers in women who underwent vaginal delivery and women who underwent cesarean delivery revealed similar pain scores. Vaginal delivery was associated with greater early ambulation than cesarean delivery. This observation confounds the importance of using pain scores or opioid consumption as the prime quality of care indicators in obstetric anesthesia and analgesia.

Enhanced functional recovery is becoming a prime success indicator of modern perioperative healthcare [144]. The Quality-of-Recovery (QoR-40) score [145] and QoR-15 [146] have been extensively studied to measure the recovery outcome following general surgery. However, neither tool is focused on the obstetric population. To date, the global measure of patient outcomes focusing on obstetric patients, 


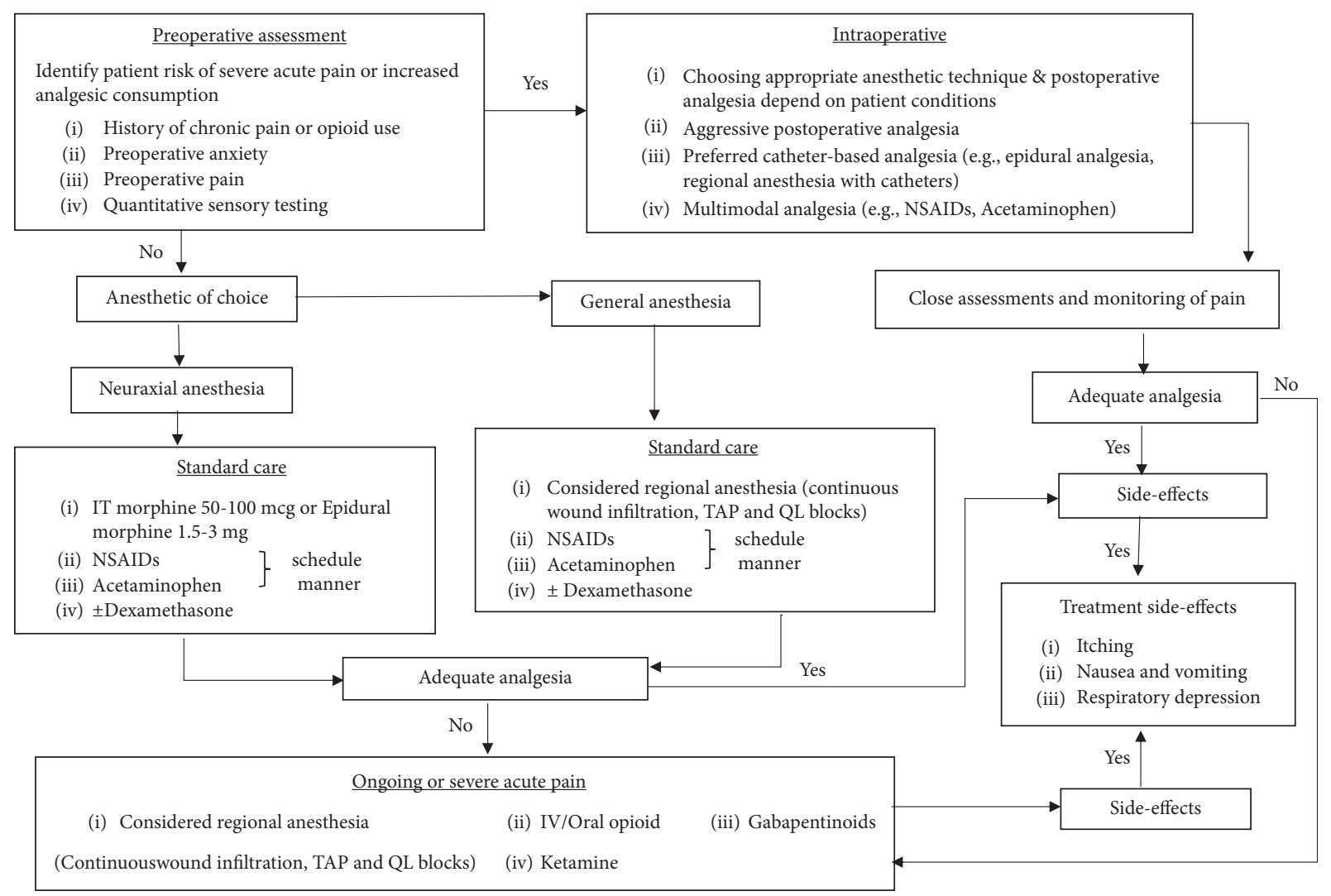

Figure 1: Stepwise multimodal analgesia for postcesarean delivery pain control.

namely, the "Obstetric Quality-of-Recovery (ObsQoR-11) score," includes evaluations of physical comfort, pain relief, physical independence, emotional state, and ability to care for the baby $[17,19]$. However, ObsQoR-11 has been updated to ObsQoR-10 by combining severe and moderate pain items, based on the patient feedback. ObsQoR-10 has been validated following spontaneous, instrumental, vaginal, and cesarean delivery in multiple healthcare setting $[18,147,148]$. However, more studies are needed to validate translated versions and determine minimal important clinical change and clinically significant differences in scores.

Postpartum pain and functional recovery were more comprehensively assessed in obstetric patients. Komatsu et al. conducted a prospective observational study of 213 nulliparous patients after vaginal or cesarean delivery [5]. The patients were assessed daily until they achieved three outcomes: [1] pain resolution, [2] opioid cessation, and [3] self-assessed functional recovery from delivery. In women who underwent cesarean section, the median times to pain resolution and to functional recovery to the prepartum levels were longer than those in women who underwent vaginal delivery (time to pain resolution: 21 (IQR 14-27) vs. 14 (IQR 7-24) days; time to functional recovery: 27 (IQR 19-40) vs. 19 (IQR 11-24) days) [5]. Pain was strongly correlated with the time of functional recovery, which was 1.7 times greater in women who underwent cesarean delivery. This provided more detail regarding recovery to predelivery levels of functioning, which appears to occur mainly by pain resolution, and opioid use is more apparent after cesarean delivery than after vaginal delivery.

\section{In Conclusion}

Stepwise multimodal analgesia has been confirmed to be effective in pain management and opioid-sparing effects. The regimens currently recommended by the ERAS, SOAP, and PROSPECT guidelines are given in Table 5. Optimal intraoperative and postoperative neuraxial analgesia has always been the focus for patient undergoing cesarean delivery. Significant pain is associated with delayed recovery, poor clinical outcomes, and poor maternal-fetal bonding. The prescribed postoperative analgesic regimen should be individualized based on preoperative risk stratification for severe pain and analgesic-related adverse effects-for example, a patient with chronic pain undergoing cesarean delivery under neuraxial anesthesia. Postoperative epidural analgesia, QL blocks, or adjunct medications (e.g., ketamine or gabapentinoids) may be beneficial to optimize analgesia and clinical outcomes.

Stepwise multimodal protocols are recommended to reduce postoperative opioid consumption. The general approach and analgesic recommendation in patients undergoing cesarean delivery with neuraxial anesthesia include intrathecal morphine in conjunction with scheduled NSAIDs and acetaminophen (Figure 1). Additional opioid administration is reserved for breakthrough pain to avoid the risk of drug transfer to breastfeeding neonates. Further 
investigation is required to determine analgesic drugs or dose alterations based on preoperative predictions for patients at risk of severe pain. Outcomes beyond pain and analgesic use, such as functional recovery, should be determined to evaluate analgesic treatment regimens.

\section{Data Availability}

The reference data supporting this review article are from previously reported studies and datasets, which have been cited.

\section{Conflicts of Interest}

The authors declare that there are no conflicts of interest.

\section{References}

[1] L. Gibbons, J. Belizán, J. Lauer, A. Betrán, M. Merialdi, and F. Althabe, "The global numbers and costs of additionally needed and unnecessary caesarean sections performed per year: overuse as a barrier to universal coverage health systems financing," World Health Report, vol. 2010, p. 30, 2010.

[2] F. Menacker and B. E. Hamilton, "Recent trends in cesarean delivery in the United States," NCHS Data Brief, vol. 35, pp. 1-8, 2010.

[3] M. F. MacDorman, F. Menacker, and E. Declercq, "Cesarean birth in the United States: epidemiology, trends, and outcomes," Clinics in Perinatology, vol. 35, no. 2, pp. 293-307, 2008.

[4] B. Carvalho, S. E. Cohen, S. S. Lipman, A. Fuller, A. D. Mathusamy, and A. Macario, "Patient preferences for anesthesia outcomes associated with cesarean delivery," Anesthesia \& Analgesia, vol. 101, no. 4, pp. 1182-1187, 2005, table of contents.

[5] R. Komatsu, B. Carvalho, and P. D. Flood, "Recovery after nulliparous birth," Anesthesiology, vol. 127, no. 4, pp. 684-694, 2017.

[6] A. Karlström, R. Engström-Olofsson, K. G. Norbergh, M. Sjöling, and I. Hildingsson, "Postoperative pain after cesarean birth affects breastfeeding and infant care," Journal of Obstetric, Gynecologic, and Neonatal Nursing, vol. 36, no. 5, pp. 430-440, 2007.

[7] J. C. Eisenach, P. H. Pan, R. Smiley, P. Lavand'homme, R. Landau, and T. T. Houle, "Severity of acute pain after childbirth, but not type of delivery, predicts persistent pain and postpartum depression," Pain, vol. 140, no. 1, pp. 87-94, 2008.

[8] S. Weibel, K. Neubert, Y. Jelting et al., "Incidence and severity of chronic pain after caesarean section," European Journal of Anaesthesiology, vol. 33, no. 11, pp. 853-865, 2016.

[9] R. Sinatra, "Causes and consequences of inadequate management of acute pain," Pain Medicine, vol. 11, no. 12, pp. 1859-1871, 2010.

[10] G. P. Joshi and B. O. Ogunnaike, "Consequences of inadequate postoperative pain relief and chronic persistent postoperative pain," Anesthesiology Clinics of North America, vol. 23, no. 1, pp. 21-36, 2005.

[11] M. J. Cousins, F. Brennan, and D. B. Carr, "Pain relief: a universal human right," Pain, vol. 112, no. 1-2, pp. 1-4, 2004.

[12] F. Brennan, D. B. Carr, and M. Cousins, "Pain management: a fundamental human right," Anesthesia \& Analgesia, vol. 105, no. 1, pp. 205-221, 2007.
[13] A. Atchabahian and M. Andreae, "Long-term functional outcomes after regional anesthesia," ASA Refresher Courses in Anesthesiology, vol. 43, no. 1, pp. 15-26, 2015.

[14] C. Eskicioglu, S. S. Forbes, M.-A. Aarts, A. Okrainec, and R. S. McLeod, "Enhanced recovery after surgery (ERAS) programs for patients having colorectal surgery: a metaanalysis of randomized trials," Journal of Gastrointestinal Surgery, vol. 13, no. 12, pp. 2321-2329, 2009.

[15] L. Bollag, G. Lim, P. Sultan, A. S. Habib, R. Landau, M. Zakowski et al., "Society for obstetric anesthesia and perinatology: consensus statement and recommendations for enhanced recovery after cesarean," Anesthesia and analgesia, vol. 44, 2020.

[16] G. A. Macones, A. B. Caughey, S. L. Wood et al., "Guidelines for postoperative care in cesarean delivery: enhanced Recovery after Surgery (ERAS) Society recommendations (part 3)," American Journal of Obstetrics and Gynecology, vol. 221, no. 3, p. 247, 2019.

[17] S. Ciechanowicz, R. Howle, C. Heppolette, B. Nakhjavani, B. Carvalho, and P. Sultan, "Evaluation of the Obstetric Quality-of-Recovery score (ObsQoR-11) following nonelective caesarean delivery," International Journal of $\mathrm{Ob}$ stetric Anesthesia, vol. 39, pp. 51-59, 2019.

[18] P. Sultan, F. Kormendy, S. Nishimura, B. Carvalho, N. Guo, and C. Papageorgiou, "Comparison of spontaneous versus operative vaginal delivery using Obstetric Quality of Recovery-10 (ObsQoR-10): an observational cohort study," Journal of Clinical Anesthesia, vol. 63, Article ID 109781, 2020.

[19] S. Ciechanowicz, T. Setty, E. Robson et al., "Development and evaluation of an obstetric quality-of-recovery score (ObsQoR-11) after elective Caesarean delivery," British journal of anaesthesia, vol. 122, no. 1, pp. 69-78, 2019.

[20] H. Y. V. Ip, A. Abrishami, P. W. H. Peng, J. Wong, and F. Chung, "Predictors of postoperative pain and analgesic consumption," Anesthesiology, vol. 111, no. 3, pp. 657-677, 2009.

[21] S. Orbach-Zinger, A. Aviram, S. Fireman et al., "Severe pain during local infiltration for spinal anaesthesia predicts postcaesarean pain," European Journal of Pain, vol. 19, no. 9, pp. 1382-1388, 2015.

[22] P. H. Pan, R. Coghill, T. T. Houle et al., "Multifactorial preoperative predictors for postcesarean section pain and analgesic requirement," Anesthesiology, vol. 104, no. 3, pp. 417-425, 2006.

[23] L. Strulov, E. Z. Zimmer, M. Granot, A. Tamir, P. Jakobi, and L. Lowenstein, "Pain catastrophizing, response to experimental heat stimuli, and post-cesarean section pain," The Journal of Pain, vol. 8, no. 3, pp. 273-279, 2007.

[24] J. J. I. Chan, C. W. Tan, C. T. Yeam et al., "Risk factors associated with development of acute and sub-acute postcesarean pain: a prospective cohort study," Journal of Pain Research, vol. 13, pp. 2317-2328, 2020.

[25] P. H. Pan, A. M. Tonidandel, C. A. Aschenbrenner, T. T. Houle, L. C. Harris, and J. C. Eisenach, "Predicting acute pain after cesarean delivery using three simple questions," Anesthesiology, vol. 118, no. 5, pp. 1170-1179, 2013.

[26] B. Carvalho, F. Mirza, and P. Flood, "Patient choice compared with no choice of intrathecal morphine dose for caesarean analgesia: a randomized clinical trial," British journal of anaesthesia, vol. 118, no. 5, pp. 762-771, 2017.

[27] B. Carvalho, C. D. Sutton, J. J. Kowalczyk, and P. D. Flood, "Impact of patient choice for different postcesarean delivery analgesic protocols on opioid consumption: a randomized 
prospective clinical trial," Regional Anesthesia \& Pain Medicine, vol. 44, no. 5, pp. 578-585, 2019.

[28] N. C. Borges, L. V. Pereira, L. A. de Moura, T. C. Silva, and C. F. Pedroso, "Predictors for moderate to severe acute postoperative pain after cesarean section," Pain Research \& Management, vol. 2016, Article ID 5783817, 2016.

[29] U. Gorkem, C. Togrul, Y. Sahiner, E. Yazla, and T. Gungor, "Preoperative anxiety may increase postcesarean delivery pain and analgesic consumption," Minerva Anestesiologica, vol. 82, no. 9, pp. 974-980, 2016.

[30] L. Z. Wang, C. N. Wei, F. Xiao, X. Y. Chang, and Y. F. Zhang, "Incidence and risk factors for chronic pain after elective caesarean delivery under spinal anaesthesia in a Chinese cohort: a prospective study," International Journal of $\mathrm{Ob}$ stetric Anesthesia, vol. 34, pp. 21-27, 2018.

[31] L. Buhagiar, O. Cassar, M. Brincat et al., "Predictors of postcaesarean section pain and analgesic consumption," Journal of Anaesthesiology Clinical Pharmacology, vol. 27, no. 2, pp. 185-191, 2011.

[32] M. Granot, L. Lowenstein, D. Yarnitsky, A. Tamir, and E. Z. Zimmer, "Postcesarean section pain prediction by preoperative experimental pain assessment," Anesthesiology, vol. 98, no. 6, pp. 1422-1426, 2003.

[33] R. Komatsu, B. Carvalho, and P. Flood, "Prediction of outliers in pain, analgesia requirement, and recovery of function after childbirth: a prospective observational cohort study," British journal of anaesthesia, vol. 121, no. 2, pp. 417-426, 2018.

[34] "Practice guidelines for obstetric anesthesia: an updated report by the American society of anesthesiologists task force on obstetric anesthesia," Anesthesiology, vol. 106, no. 4, pp. 843-863, 2007.

[35] S. E. Cohen, L. L. Subak, W. G. Brose, and J. Halpern, "Analgesia after cesarean delivery: patient evaluations and costs of five opioid techniques," Regional Anesthesia, vol. 16, no. 3, pp. 141-149, 1991.

[36] H. J. McQuay, A. F. Sullivan, K. Smallman, and A. H. Dickenson, "Intrathecal opioids, potency and lipophilicity," Pain, vol. 36, no. 1, pp. 111-115, 1989.

[37] A. Hindle, "Intrathecal opioids in the management of acute postoperative pain," Continuing Education in Anaesthesia, Critical Care \& Pain, vol. 8, no. 3, pp. 81-85, 2008.

[38] J. B. Dahl, I. S. Jeppesen, H. Jørgensen, J. Wetterslev, and S. Møiniche, "Intraoperative and postoperative analgesic efficacy and adverse effects of intrathecal opioids in patients undergoing cesarean section with spinal anesthesia," Anesthesiology, vol. 91, no. 6, p. 1919, 1999.

[39] P. Sultan, S. H. Halpern, E. Pushpanathan, S. Patel, and B. Carvalho, "The effect of intrathecal morphine dose on outcomes after elective cesarean delivery," Anesthesia \& Analgesia, vol. 123, no. 1, pp. 154-164, 2016.

[40] J. S. Berger, A. Gonzalez, A. Hopkins et al., "Dose-response of intrathecal morphine when administered with intravenous ketorolac for post-cesarean analgesia: a two-center, prospective, randomized, blinded trial," International Journal of Obstetric Anesthesia, vol. 28, pp. 3-11, 2016.

[41] L. Aiono-Le Tagaloa, A. J. Butwick, and B. Carvalho, "A survey of perioperative and postoperative anesthetic practices for cesarean delivery," Anesthesiology research and practice, vol. 2009, p. 510642, 2009.

[42] J. Sarvela, P. Halonen, A. Soikkeli, and K. Korttila, "A double-blinded, randomized comparison of intrathecal and epidural morphine for elective cesarean delivery," Anesthesia \& Analgesia, vol. 95, no. 2, pp. 436-440, 2002.
[43] C. Dualé, C. Frey, F. Bolandard, A. Barrière, and P. Schoeffler, "Epidural versus intrathecal morphine for postoperative analgesia after Caesarean section," British journal of anaesthesia, vol. 91, no. 5, pp. 690-694, 2003.

[44] J. G. Fuller, G. H. McMorland, M. J. Douglas, and L. Palmer, "Epidural morphine for analgesia after caesarean section: a report of 4880 patients," Canadian Journal of Anaesthesia, vol. 37, no. 6, pp. 636-640, 1990.

[45] C. M. Palmer, W. M. Nogami, G. Van Maren, and D. M. Alves, "Postcesarean epidural morphine: a dose-response study," Anesthesia \& Analgesia, vol. 9, no. 4, pp. 887-891, 2000.

[46] S. I. Singh, S. Rehou, K. L. Marmai, and A. P. M. Jones, "The efficacy of 2 doses of epidural morphine for postcesarean delivery analgesia," Anesthesia \& Analgesia, vol. 117, no. 3, pp. 677-685, 2013.

[47] R. Chou, D. B. Gordon, O. A. De Leon-Casasola et al., "Management of postoperative pain: a clinical practice guideline from the American pain society, the American society of regional anesthesia and pain medicine, and the American society of anesthesiologists' committee on regional anesthesia, executive committee, and administrative council," The Journal of Pain, vol. 17, no. 2, pp. 131-157, 2016.

[48] R. Landau, "Post-cesarean delivery pain. Management of the opioid-dependent patient before, during and after cesarean delivery," International Journal of Obstetric Anesthesia, vol. 39, pp. 105-116, 2019.

[49] O. Adesope, U. Ituk, and A. S. Habib, "Local anaesthetic wound infiltration for postcaesarean section analgesia," European Journal of Anaesthesiology, vol. 33, no. 10, pp. 731-742, 2016.

[50] C. Jolly, F. Jathières, H. Keïta, E. Jaouen, B. Guyot, and A. Torre, "Cesarean analgesia using levobupivacaine continuous wound infiltration: a randomized trial," European Journal of Obstetrics \& Gynecology and Reproductive Biology, vol. 194, pp. 125-130, 2015.

[51] G. Ducarme, S. Sillou, A. Wernet et al., "Intérêt de l'instillation pariétale unique de ropivacaïne dans la prévention des douleurs après césarienne," Gynecologie Obstetrique \& Fertilite, vol. 40, no. 1, pp. 10-13, 2012.

[52] T. Corsini, P. Cuvillon, A. Forgeot, C. Chapelle, P. Seffert, and C. Chauleur, "Infiltration peropératoire de lévobupivacaïne après césariennes: étude randomisée en double insu contre placebo," Annales Françaises d'Anesthesie et de Reanimation, vol. 32, no. 1, pp. 25-30, 2013.

[53] T. Rackelboom, S. L. Strat, S. Silvera et al., "Improving continuous wound infusion effectiveness for postoperative analgesia after cesarean delivery," Obstetrics \& Gynecology, vol. 116, no. 4, pp. 893-900, 2010.

[54] J. P. Kainu, J. Sarvela, P. Halonen et al., "Continuous wound infusion with ropivacaine fails to provide adequate analgesia after caesarean section," International Journal of Obstetric Anesthesia, vol. 21, no. 2, pp. 119-124, 2012.

[55] P. M. Lavand'homme, F. Roelants, H. Waterloos, and M. F. De Kock, "Postoperative analgesic effects of continuous wound infiltration with diclofenac after elective cesarean delivery," Anesthesiology, vol. 106, no. 6, pp. 1220-1225, 2007.

[56] D. W. J. Mecklem, M. D. Humphrey, and R. W. Hicks, "Efficacy of bupivacaine delivered by wound catheter for post-Caesarean section analgesia," The Australian and New Zealand Journal of Obstetrics and Gynaecology, vol. 35, no. 4, pp. 416-421, 1995. 
[57] R. Ton, D. W. Stovall, and C. Rhoades-Lazenby, "The effects of infiltration of liposomal bupivacaine for pain control after cesarean delivery: a randomized trial [19T]," Obstetrics \& Gynecology, vol. 133, no. 1, p. 218S, 2019.

[58] M. Prabhu, M. A. Clapp, E. McQuaid-Hanson et al., "Liposomal bupivacaine block at the time of cesarean delivery to decrease postoperative pain," Obstetrics \& Gynecology, vol. 132, no. 1, pp. 70-78, 2018.

[59] P. Sultan, S. D. Patel, S. Jadin, B. Carvalho, and S. H. Halpern, "Transversus abdominis plane block compared with wound infiltration for postoperative analgesia following Cesarean delivery: a systematic review and network meta-analysis," Canadian Journal of Anesthesia/Journal canadien d'anesthésie, vol. 67, no. 12, pp. 1710-1727, 2020.

[60] D. Q. Tran, D. Bravo, P. Leurcharusmee, and J. M. Neal, "Transversus abdominis plane block," Anesthesiology, vol. 131, no. 5, pp. 1166-1190, 2019.

[61] J. G. McDonnell, G. Curley, J. Carney et al., "The analgesic efficacy of transversus abdominis plane block after cesarean delivery: a randomized controlled trial," Anesthesia \& Analgesia, vol. 106, no. 1, pp. 186-191, 2008.

[62] S. H. R. Faiz, M. R. Alebouyeh, P. Derakhshan, F. Imani, P. Rahimzadeh, and M. Ghaderi Ashtiani, "Comparison of ultrasound-guided posterior transversus abdominis plane block and lateral transversus abdominis plane block for postoperative pain management in patients undergoing cesarean section: a randomized double-blind clinical trial study," Journal of Pain Research, vol. 11, pp. 5-9, 2018.

[63] R. Champaneria, L. Shah, M. J. Wilson, and J. P. Daniels, "Clinical effectiveness of transversus abdominis plane (TAP) blocks for pain relief after caesarean section: a meta-analysis," International Journal of Obstetric Anesthesia, vol. 28, pp. 45-60, 2016.

[64] S. S. Nedeljkovic, A. Kett, M. C. Vallejo et al., "Transversus abdominis plane block with liposomal bupivacaine for pain after cesarean delivery in a multicenter, randomized, doubleblind, controlled trial," Anesthesia \& Analgesia, vol. 131, no. 6, pp. 1830-1839, 2020.

[65] M. Chandon, A. Bonnet, Y. Burg et al., "Ultrasound-guided Transversus Abdominis plane block versus continuous wound infusion for post-caesarean analgesia: a randomized trial," PLoS One, vol. 9, no. 8, Article ID e103971, 2014.

[66] E. Weiss, C. Jolly, J.-L. Dumoulin et al., "Convulsions in 2 patients after bilateral ultrasound-guided transversus abdominis plane blocks for cesarean analgesia," Regional Anesthesia and Pain Medicine, vol. 39, no. 3, pp. 248-251, 2014.

[67] P. Rosenberg, B. Veering, and W. Urmey, "Maximum recommended doses of local anesthetics: a multifactorial concept," Regional Anesthesia and Pain Medicine, vol. 29, no. 6, pp. 564-575, 2004, discussion 24.

[68] S. C. Ng, A. S. Habib, S. Sodha, B. Carvalho, and P. Sultan, "High-dose versus low-dose local anaesthetic for transversus abdominis plane block post-Caesarean delivery analgesia: a meta-analysis," British journal of anaesthesia, vol. 120, no. 2, pp. 252-263, 2018.

[69] F. W. Abdallah, V. W. Chan, and R. Brull, "Transversus abdominis plane block," Regional Anesthesia and Pain Medicine, vol. 37, no. 2, pp. 193-209, 2012.

[70] S. Moeschler, N. S. Pingree, B. C. Hoelzer, H. M. Rho, R. H. Murthy, and M. J. Gazelka, "Ultrasound-guided transversus abdominis plane injection with computed tomography correlation: a cadaveric study," Journal of Pain Research, vol. 6, pp. 493-496, 2013.
[71] H. Elsharkawy, K. El-Boghdadly, S. Kolli et al., "Injectate spread following anterior sub-costal and posterior approaches to the quadratus lumborum block," European Journal of Anaesthesiology, vol. 34, no. 9, pp. 587-595, 2017.

[72] A. L. Balocco, A. M. López, C. Kesteloot et al., "Quadratus lumborum block: an imaging study of three approaches," Regional Anesthesia \& Pain Medicine, vol. 46, no. 1, pp. 35-40, 2021.

[73] H. Elsharkawy, S. Ahuja, S. DeGrande, K. Maheshwari, and V. Chan, "Subcostal approach to anterior quadratus lumborum block for pain control following open urological procedures," Journal of Anesthesia, vol. 33, no. 1, pp. 148-154, 2019.

[74] L. Benetazzo, A. Bizzego, R. De Caro, G. Frigo, D. Guidolin, and C. Stecco, "3D reconstruction of the crural and thoracolumbar fasciae," Surgical and Radiologic Anatomy, vol. 33, no. 10, pp. 855-862, 2011.

[75] R. Blanco, T. Ansari, W. Riad, and N. Shetty, "Quadratus lumborum block versus transversus abdominis plane block for postoperative pain after cesarean delivery," Regional Anesthesia and Pain Medicine, vol. 41, no. 6, pp. 757-762, 2016.

[76] R. Blanco, T. Ansari, and E. Girgis, "Quadratus lumborum block for postoperative pain after caesarean section," European Journal of Anaesthesiology, vol. 32, no. 11, pp. 812818, 2015.

[77] M. Xu, Y. Tang, J. Wang, and J. Yang, "Quadratus lumborum block for postoperative analgesia after cesarean delivery: a systematic review and meta-analysis," International Journal of Obstetric Anesthesia, vol. 42, pp. 87-98, 2020.

[78] H. S. Tan, C. Taylor, D. Weikel, K. Barton, and A. S. Habib, "Quadratus lumborum block for postoperative analgesia after cesarean delivery: a systematic review with metaanalysis and trial-sequential analysis," Journal of Clinical Anesthesia, vol. 67, p. 110003, 2020.

[79] P. Pangthipampai, S. Dejarkom, S. Poolsuppasit, C. Luansritisakul, and S. Tangchittam, "Bilateral posterior Quadratus Lumborum block for pain relief after cesarean delivery: a randomized controlled trial," BMC Anesthesiology, vol. 21, no. 1, p. 90, 2021.

[80] T. Tamura, S. Yokota, M. Ando, Y. Kubo, and K. Nishiwaki, "A triple-blinded randomized trial comparing spinal morphine with posterior quadratus lumborum block after cesarean section," International Journal of Obstetric Anesthesia, vol. 40, pp. 32-38, 2019.

[81] W. Kang, D. Lu, X. Yang et al., "Postoperative analgesic effects of various quadratus lumborum block approaches following cesarean section: a randomized controlled trial," Journal of Pain Research, vol. 12, pp. 2305-2312, 2019.

[82] E. R. Salama, "Ultrasound-guided bilateral quadratus lumborum block vs. intrathecal morphine for postoperative analgesia after cesarean section: a randomized controlled trial," Korean journal of anesthesiology, vol. 73, no. 2, pp. 121-128, 2020.

[83] R. Irwin, S. Stanescu, C. Buzaianu et al., "Quadratus lumborum block for analgesia after caesarean section: a randomised controlled trial," Anaesthesia, vol. 75, no. 1, pp. 89-95, 2020.

[84] T. Murouchi, S. Iwasaki, and M. Yamakage, "Quadratus lumborum block," Regional Anesthesia and Pain Medicine, vol. 41, no. 2, pp. 146-150, 2016.

[85] H. Ueshima and O. Hiroshi, "Incidence of lower-extremity muscle weakness after quadratus lumborum block," Journal of Clinical Anesthesia, vol. 44, p. 104, 2018. 
[86] M. Sá, J. M. Cardoso, H. Reis et al., "Quadratus lumborum block: are we aware of its side effects? A report of 2 cases," Brazilian Journal of Anesthesiology (English Edition), vol. 68, no. 4, pp. 396-399, 2018.

[87] A. Krohg, K. Ullensvang, L. A. Rosseland, E. Langesæter, and A. R. Sauter, "The analgesic effect of ultrasound-guided quadratus lumborum block After cesarean delivery," Anesthesia \& Analgesia, vol. 126, no. 2, pp. 559-565, 2018.

[88] H. Elsharkawy, K. El-Boghdadly, and M. Barrington, "Quadratus lumborum block," Anesthesiology, vol. 130, no. 2, pp. 322-335, 2019.

[89] E. Maund, C. McDaid, S. Rice, K. Wright, B. Jenkins, and N. Woolacott, "Paracetamol and selective and non-selective non-steroidal anti-inflammatory drugs for the reduction in morphine-related side-effects after major surgery: a systematic review," British journal of anaesthesia, vol. 106, no. 3, pp. 292-297, 2011.

[90] A. M. Zeng, N. F. Nami, C. L. Wu, and J. D. Murphy, "The analgesic efficacy of nonsteroidal anti-inflammatory agents (NSAIDs) in patients undergoing cesarean deliveries," Regional Anesthesia and Pain Medicine, vol. 41, no. 6, pp. 763-772, 2016.

[91] G. Pavy, M. J. Paech, and S. F. Evans, "The effect of intravenous ketorolac on opioid requirement and pain after cesarean delivery," Anesthesia \& Analgesia, vol. 92, no. 4, pp. 1010-1014, 2001.

[92] ACOG Committee Opinion No. 742, "Postpartum pain management," Obstetrics \& Gynecology, vol. 132, no. 1, pp. e35-e43, 2018.

[93] J. L. Lowder, D. P. Shackelford, D. Holbert, and T. M. Beste, "A randomized, controlled trial to compare ketorolac tromethamine versus placebo after cesarean section to reduce pain and narcotic usage," American Journal of Obstetrics and Gynecology, vol. 189, no. 6, pp. 1559-1562, 2003.

[94] N. Inthigood, T. Lertbunnaphong, and A. Jaishuen, "Efficacy of a single 40-mg intravenous dose of parecoxib for postoperative pain control after elective cesarean delivery: a double-blind randomized placebo-controlled trial," Journal of Obstetrics and Gynaecology Research, vol. 43, no. 1, pp. 92-99, 2017.

[95] P. J. Angle, S. H. Halpern, B. L. Leighton, J. P. Szalai, K. Gnanendran, and J. E. Kronberg, "A randomized controlled trial examining the effect of naproxen on analgesia during the second day after cesarean delivery," Anesthesia \& Analgesia, vol. 95, no. 3, pp. 741-745, 2002.

[96] J. A. Alhashemi, Q. A. Alotaibi, M. S. Mashaat, T. M. Kaid, R. H. Mujallid, and A. M. Kaki, "Intravenous acetaminophenvs oral ibuprofen in combination with morphine PCIA after Cesarean delivery," Canadian Journal of Anesthesia/Journal canadien d'anesthésie, vol. 53, no. 12, pp. 1200-1206, 2006.

[97] P. Matsota, M. Nakou, K. Kalimeris, C. Batistaki, A. Pandazi, and G. Kostopanagiotou, “A single dose of celecoxib $200 \mathrm{mg}$ improves postoperative analgesia provided via patientcontrolled epidural technique after caesarean section," Archives of Medical Science, vol. 5, no. 5, pp. 877-882, 2013.

[98] V. Dahl, I. E. Hagen, A. M. Sveen, H. Norseng, K. S. Koss, and T. Steen, "High-dose diclofenac for postoperative analgesia after elective caesarean section in regional anaesthesia," International Journal of Obstetric Anesthesia, vol. 11, no. 2, pp. 91-94, 2002.

[99] C. I. Olofsson, M. H. Legeby, E.-B. Nygårds, and K. M. Östman, "Diclofenac in the treatment of pain after caesarean delivery," European Journal of Obstetrics \&
Gynecology and Reproductive Biology, vol. 88, no. 2, pp. 143-146, 2000.

[100] E. Roofthooft, G. P. Joshi, N. Rawal, and M. Van de Velde, "PROSPECT guideline for elective caesarean section: updated systematic review and procedure-specific postoperative pain management recommendations," Anaesthesia, vol. 32, 2020.

[101] M. R. El-Tahan, O. M. Warda, A. M. Yasseen, M. M. Attallah, and M. K. Matter, "A randomized study of the effects of preoperative ketorolac on general anaesthesia for caesarean section," International Journal of Obstetric Anesthesia, vol. 16, no. 3, pp. 214-220, 2007.

[102] M. B. Khezri, M. A. Mosallaei, M. Ebtehaj, and N. Mohammadi, "Comparison of preemptive effect of intravenous ketorolac versus meperidine on postoperative shivering and pain in patients undergoing cesarean section under spinal anesthesia: a prospective, randomized, doubleblind study," Caspian journal of internal medicine, vol. 9, no. 2, pp. 151-157, 2018.

[103] H.-L. Sun, C.-C. Wu, M.-S. Lin, C.-F. Chang, and M. S. Mok, "Combination of low-dose epidural morphine and intramuscular diclofenac sodium in postcesarean analgesia," Anesthesia \& Analgesia, vol. 75, no. 1, pp. 64-68, 1992.

[104] D. J. Bush, G. Lyons, and R. MacDonald, "Diclofenac for analgesia after caesarean section," Anaesthesia, vol. 47, no. 12, pp. 1075-1077, 1992.

[105] C. H. Wilder-Smith, L. Hill, R. A. Dyer, G. Torr, and a. Coetzee, "Postoperative sensitization and pain after cesarean delivery and the effects of single im doses of tramadol and diclofenac alone and in combination," Anesthesia \& Analgesia, vol. 97, no. 2, pp. 526-533, 2003, table of contents.

[106] A. Bourlert, "Diclofenac intramuscular single dose to decrease pain in post operative Caesarean section: a double blind randomized controlled trial," Journal of the Medical Association of Thailand = Chotmaihet thangphaet, vol. 88, no. 1, pp. 15-19, 2005.

[107] S. Thienthong, C. Chongsomchai, and W. Kemthong, "A placebo-controlled, double-blind, randomized study of single-dose intravenous diclofenac for pain relief after a cesarean section," Acta Anaesthesiologica Taiwanica, vol. 50, no. 4, pp. 150-152, 2012.

[108] A. Aminoshariae and A. Khan, "Acetaminophen: old drug, new issues," Journal of Endodontics, vol. 41, no. 5, pp. 588-593, 2015.

[109] B. J. Anderson, "Paracetamol (Acetaminophen): mechanisms of action," Pediatric Anesthesia, vol. 18, no. 10, pp. 915-921, 2008.

[110] B. Altenau, C. C. Crisp, C. G. Devaiah, and D. S. Lambers, "Randomized controlled trial of intravenous acetaminophen for postcesarean delivery pain control," American Journal of Obstetrics and Gynecology, vol. 217, no. 3, pp. 362-e6, 2017.

[111] O. Mathiesen, J. Wetterslev, V. K. Kontinen et al., "Adverse effects of perioperative paracetamol, NSAIDs, glucocorticoids, gabapentinoids and their combinations: a topical review," Acta Anaesthesiologica Scandinavica, vol. 58, no. 10, pp. 1182-1198, 2014.

[112] F. Bakhsha, A. S. Niaki, S. Y. Jafari, Z. Yousefi, and M. Aryaie, "The effects of diclofenac suppository and intravenous acetaminophen and their combination on the severity of postoperative pain in patients undergoing spinal anaesthesia during cesarean section," Journal of Clinical and Diagnostic Research: Journal of Clinical and Diagnostic Research, vol. 10, no. 7, pp. Uc09-12, 2016. 
[113] B. Munishankar, P. Fettes, C. Moore, and G. A. McLeod, "A double-blind randomised controlled trial of paracetamol, diclofenac or the combination for pain relief after caesarean section," International Journal of Obstetric Anesthesia, vol. 17, no. 1, pp. 9-14, 2008.

[114] B. Carvalho and A. J. Butwick, "Postcesarean delivery analgesia," Best Practice \& Research Clinical Anaesthesiology, vol. 31, no. 1, pp. 69-79, 2017.

[115] A. R. Valentine, B. Carvalho, T. A. Lazo, and E. T. Riley, "Scheduled acetaminophen with as-needed opioids compared to as-needed acetaminophen plus opioids for postcesarean pain management," International Journal of $\mathrm{Ob}$ stetric Anesthesia, vol. 24, no. 3, pp. 210-216, 2015.

[116] S. H. Wilson, B. J. Wolf, S. M. Robinson, C. Nelson, and L. Hebbar, "Intravenous vs oral acetaminophen for analgesia after cesarean delivery: a randomized trial," Pain Medicine, vol. 20, no. 8, pp. 1584-1591, 2019.

[117] S. M. Siddik, M. T. Aouad, M. I. Jalbout, L. B. Rizk, G. H. Kamar, and A. S. Baraka, "Diclofenac and/or propacetamol for postoperative pain management after cesarean delivery in patients receiving patient controlled analgesia morphine," Regional Anesthesia and Pain Medicine, vol. 26, no. 4, pp. 310-315, 2001.

[118] M. J. Paech, N. J. McDonnell, A. Sinha, C. Baber, and E. A. Nathan, "A randomised controlled trial of parecoxib, celecoxib and paracetamol as adjuncts to patient-controlled epidural analgesia after caesarean delivery," Anaesthesia \& Intensive Care, vol. 42, no. 1, pp. 15-22, 2014.

[119] O. Ozmete, C. Bali, O. Y. Cok et al., "Preoperative paracetamol improves post-cesarean delivery pain management: a prospective, randomized, double-blind, placebo-controlled trial," Journal of Clinical Anesthesia, vol. 33, pp. 51-57, 2016.

[120] C. V. Towers, S. Shelton, J. van Nes et al., "Preoperative cesarean delivery intravenous acetaminophen treatment for postoperative pain control: a randomized double-blinded placebo control trial," American Journal of Obstetrics and Gynecology, vol. 218, no. 3, p. 353, 2018.

[121] G. S. De Oliveira, L. J. S. Castro-Alves, S. Ahmad, M. C. Kendall, and R. J. McCarthy, "Dexamethasone to prevent postoperative nausea and vomiting," Anesthesia \& Analgesia, vol. 116, no. 1, pp. 58-74, 2013.

[122] P. Shalu and P. Ghodki, "To study the efficacy of intravenous dexamethasone in prolonging the duration of spinal anesthesia in elective cesarean section," Anesthesia: Essays and Researches, vol. 11, no. 2, pp. 321-325, 2017.

[123] U. Ituk and K. Thenuwara, "The effect of a single intraoperative dose of intravenous dexamethasone $8 \mathrm{mg}$ on postcesarean delivery analgesia: a randomized controlled trial," International Journal of Obstetric Anesthesia, vol. 35, pp. 57-63, 2018.

[124] M. M. S. Cardoso, A. O. Leite, E. A. Santos, J. L. Gozzani, and L. A. S. T. Mathias, "Effect of dexamethasone on prevention of postoperative nausea, vomiting and pain after caesarean section," European Journal of Anaesthesiology, vol. 30, no. 3, pp. 102-105, 2013.

[125] N. P. Edomwonyi, M. O. Osazuwa, O. I. Iribhogbe, and S. E. Esangbedo, "Postoperative analgesia using bupivacaine wound infiltration with intravenous tramadol or dexamethasone following obstetric spinal anaesthesia," Nigerian Journal of Clinical Practice, vol. 20, no. 12, pp. 1584-1589, 2017.

[126] S. Patnaik, S. Singh, D. Vivekanand, T. P. Singh, and Saurav, "Evaluation of quality of recovery score in mothers and neonatal outcome assessment after surgery using preoperative dexamethasone for caesarean section," Medical Journal Armed Forces India, vol. 77, no. 2, pp. 170-174, 2021.

[127] T. K. Allen, C. A. Jones, and A. S. Habib, "Dexamethasone for the prophylaxis of postoperative nausea and vomiting associated with neuraxial morphine administration," Anesthesia \& Analgesia, vol. 114, no. 4, pp. 813-822, 2012.

[128] Y.-C. Cai, L. Ma, G.-H. Fan, J. Zhao, L.-Z. Jiang, and G. Pei, "Activation of N-Methyl-d-Aspartate receptor attenuates acute responsiveness of $\delta$-opioid receptors," Molecular Pharmacology, vol. 51, no. 4, pp. 583-587, 1997.

[129] R. Lydic and H. A. Baghdoyan, "Ketamine and MK-801 decrease acetylcholine release in the pontine reticular formation, slow breathing, and disrupt sleep," Sleep, vol. 25, no. 6, pp. 617-622, 2002.

[130] T. Yamakura, L. E. Chavez-Noriega, and R. A. Harris, "Subunit-dependent inhibition of human neuronal nicotinic acetylcholine receptors and other ligand-gated ion channels by dissociative anesthetics ketamine and dizocilpine," $A n$ esthesiology, vol. 92, no. 4, pp. 1144-1153, 2000.

[131] M. Wang, A. H. Wong, and F. Liu, "Interactions between NMDA and dopamine receptors: a potential therapeutic target," Brain Research, vol. 1476, pp. 154-163, 2012.

[132] S. Sen, G. Ozmert, O. N. Aydin, N. Baran, and E. Calskan, "The persisting analgesic effect of low-dose intravenous ketamine after spinal anaesthesia for caesarean section," European Journal of Anaesthesiology, vol. 22, no. 7, pp. 518-523, 2005.

[133] S. Y. Han, H. C. Jin, W. D. Yang et al., "The effect of low-dose ketamine on post-caesarean delivery analgesia after spinal anesthesia," The Korean journal of pain, vol. 26, no. 3, pp. 270-276, 2013.

[134] J. R. Bauchat, N. Higgins, K. G. Wojciechowski, R. J. McCarthy, P. Toledo, and C. A. Wong, "Low-dose ketamine with multimodal postcesarean delivery analgesia: a randomized controlled trial," International Journal of $\mathrm{Ob}$ stetric Anesthesia, vol. 20, no. 1, pp. 3-9, 2011.

[135] M. Heesen, J. Böhmer, E. C. V. Brinck et al., "Intravenous ketamine during spinal and general anaesthesia for caesarean section: systematic review and meta-analysis," Acta Anaesthesiologica Scandinavica, vol. 59, no. 4, pp. 414-426, 2015.

[136] C. D. Sutton and B. Carvalho, "Optimal pain management after cesarean delivery," Anesthesiology Clinics, vol. 35, no. 1, pp. 107-124, 2017.

[137] H. Clarke, R. P. Bonin, B. A. Orser, M. Englesakis, D. N. Wijeysundera, and J. Katz, "The prevention of chronic postsurgical pain using gabapentin and pregabalin," Anesthesia \& Analgesia, vol. 115, no. 2, pp. 428-442, 2012.

[138] E. M. Tiippana, K. Hamunen, V. K. Kontinen, and E. Kalso, "Do surgical patients benefit from perioperative gabapentin/ pregabalin? A systematic review of efficacy and safety," Anesthesia \& Analgesia, vol. 104, no. 6, pp. 1545-1556, 2007.

[139] A. Moore, J. Costello, P. Wieczorek, V. Shah, A. Taddio, and J. C. A. Carvalho, "Gabapentin improves postcesarean delivery pain management," Anesthesia \& Analgesia, vol. 112, no. 1, pp. 167-173, 2011.

[140] D. T. Monks, D. W. Hoppe, K. Downey, V. Shah, P. Bernstein, and J. C. A. Carvalho, "A perioperative course of gabapentin does not produce a clinically meaningful improvement in analgesia after cesarean delivery," Anesthesiology, vol. 123, no. 2, pp. 320-326, 2015.

[141] J. Short, K. Downey, P. Bernstein, V. Shah, and J. C. A. Carvalho, "A single preoperative dose of gabapentin does not improve postcesarean delivery pain management," Anesthesia \& Analgesia, vol. 115, no. 6, pp. 1336-1342, 2012. 
[142] L. Felder, G. Saccone, S. Scuotto et al., "Perioperative gabapentin and post cesarean pain control: a systematic review and meta-analysis of randomized controlled trials," European Journal of Obstetrics \& Gynecology and Reproductive Biology, vol. 233, pp. 98-106, 2019.

[143] J. H. Kristensen, K. F. Ilett, L. P. Hackett, and R. Kohan, "Gabapentin and breastfeeding: a case report," Journal of Human Lactation, vol. 22, no. 4, pp. 426-428, 2006.

[144] P. S. Myles, "Perioperative outcomes: are we asking the right questions?" Canadian Journal of Anesthesia/Journal canadien d'anesthésie, vol. 63, no. 2, pp. 138-141, 2016.

[145] P. S. Myles, B. Weitkamp, K. Jones, J. Melick, and S. Hensen, "Validity and reliability of a postoperative quality of recovery score: the QoR-40," British journal of anaesthesia, vol. 84, no. 1, pp. 11-15, 2000.

[146] P. A. Stark, P. S. Myles, and J. A. Burke, "Development and psychometric evaluation of a postoperative quality of recovery score," Anesthesiology, vol. 118, no. 6, pp. 1332-1340, 2013.

[147] P. Sultan, N. Kamath, B. Carvalho et al., "Evaluation of inpatient postpartum recovery using the obstetric quality of recovery-10 patient-reported outcome measure: a singlecenter observational study," American Journal of Obstetrics \& Gynecology MFM, vol. 2, no. 4, Article ID 100202, 2020.

[148] S. Shalev, S. Orbach-Zinger, P. Sultan et al., "Obstetric quality of recovery scoring tool: assessment of validity, reliability and feasibility in an Israeli cesarean delivery population," International Journal of Obstetric Anesthesia, vol. 44, p. 51, 2020. 